WMP-28119

Revision 0

\title{
Mending the In Situ Redox Manipulation Barrier
}

Prepared for the U.S. Department of Energy

Assistant Secretary for Environmental Management

Project Hanford Management Contractor for the

U.S. Department of Energy under Contract DE-AC06-96RL13200

\section{Fluor Hanford}

P.O. Box 1000

Richland, Washington

Approved for Public Release;

Further Dissemination Unlimited 
WMP-28119

Revision 0

\section{Mending the In Situ Redox Manipulation Barrier}

Document Type: $\mathrm{TI}$

S. W. Petersen

Fluor Hanford, Inc.

D. Kaback

CTC

T.W. Fogwell

Fluor Hanford, Inc.

B. Wielinga

MFG, Inc.
Program/Project: WMP

K. Cantrell

PNNL

D. Ralston

Ralston Hydrogeological Services

R. Ghosh

RETEC

S. Morrison

SM Stoller

Date Published

December 2005

Prepared for the U.S. Department of Energy

Assistant Secretary for Environmental Management

Project Haniford Management Contractor for the

U.S. Department of Energy under Contract DE-AC06-96RL13200

\section{Fluor Hanford}

P.O. Box 1000

Richland, Washington

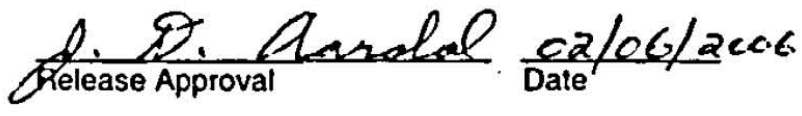


WMP-28119

Revision 0

TRADEMARK DISCLAIMER

Reterence herein to any specific commercial product, process,

or service by trade name, trademark, manufacturer, or

otherwise, does not necessarily constitute or imply its

endorsement, recommendation, or lavoring by the United

States Government or any agency thereof or its contractors or subcontractors.

This report has been reproduced from the best available copy. 
Page 6 of 93 of DA01912029

WMP-28119

Revision 0

APPROVAL PAGE

Title:

Approvals:
Mending the In Situ Redox Manipulation Barrier

T. W. Fogwell

Manager, Integration and Assessment, Groundwater Remediation Project

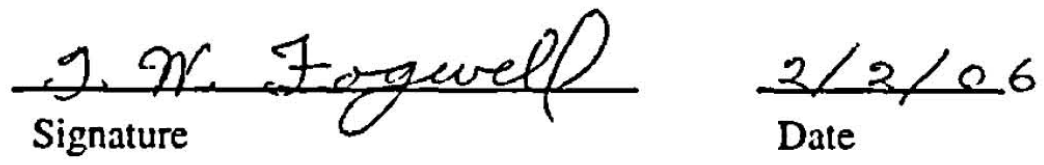

J. G. Riddelle

Manager_Enginecring, Groundwater Remediation Project

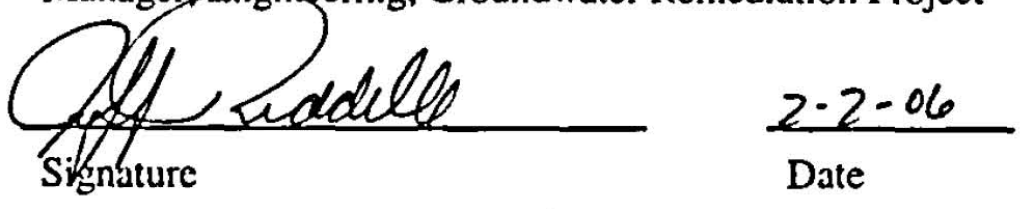

J. A. Winterhalder

Environmental Compliance Officer, Groundwater Remediation Project

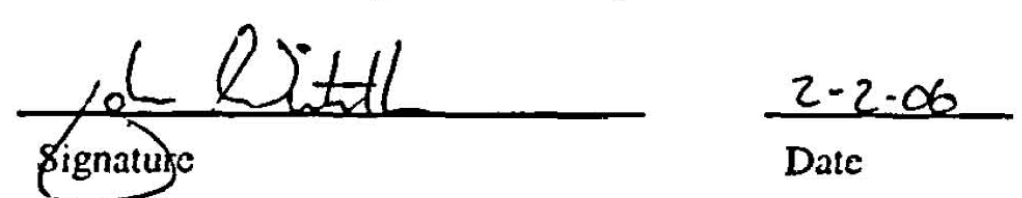

S. W. Petersen

Task Lead, Groundwater Remediation Project

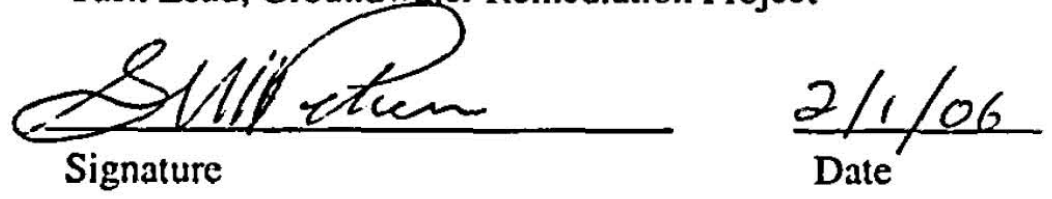


WMP-28119

Revision 0

\section{TABLE OF CONTENTS}

EXECUTIVE SUMMARY ........................................................................................IV

1.0 INTRODUCTION....................................................................................1-1

1.1 TECINICAL ASSISTANCE REQUEST ................................................................ 1-1

1.2 SITE HISTORY, THE PROBLEM, AND THE REMEdiAL ALTERNATIVE .....................1-1

1.3 ISRM METHODOLOGY AND PERFORMANCE .................................................... 1-1

1.4 TECHNICAL ASSISTANCE OBJECTIVES AND METHODOLOGY ............................... 1-2

2.0 POTENTIAL CAUSES OF THE PROBLEM ..............................................2-1

2.1 PHIYSICAL HETEROGENEITY ....................................................................... 2-1

2.2 CHEMICAL HETEROGENEITY ......................................................................... 2-4

2.3 OTIER OXIDANTS ............................................................................................ 2-6

2.4 OTIIER POSSIBLE CAUSES ................................................................................... 2-7

2.5 SUMMARY OF POSSIBLE CAUSES.................................................................... 2-7

2.6 MAGNITUDE OF TIE PROBLEM........................................................................... 2-8

3.0 RECOMMENDATIONS FOR IMPROVED UNDERSTANDING OF THE PROBLEM (CAUSE AND MA GNITUDE) ...................................................... 3-1

3.1 DEPTH-DISCRETE CORE ANALYSIS......................................................................3-2

3.2 BOREHOLE GEOPHYSICS ................................................................................3-3

3.3 ELECTRONIC BOREHOLE FLOWMETER MEASUREMENTS.....................................3-3

3.3.1 Acquisition of Core Samples ..............................................................................3-4

3.3.2 Physical Characterization …........................................................................3-4

3.3.3 Chemical Characterization........................................................................3-5

3.4 ADDITIONAL CIIARACTERIZATION METIODS ...................................................3-5

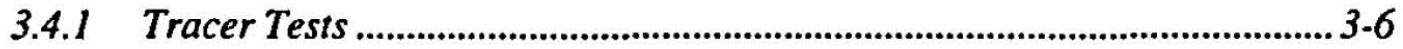

3.4.2 Hydraulic Tests ...................................................................................... 3.7

3.4.3 Modeling ............................................................................................................ 3.7

3.4.4 Cross-Borehole Geophysics............................................................................ 3-8

3.4.5 Flux Testing ............................................................................................... 3-8

3.4.6 FLUTe Conductivity Profiler.......................................................................3-9

3.4.7 Surface Geophysics...................................................................................... 3-9

3.5 SUMMARY RECOMMENDATIONS TO IMPROVE UNDERSTANDING OF THE PROBLEM

4.0 RECOMMENDATIONS FOR MENDING THE BARRIER .......................4-1

4.1 DITHIONITE..................................................................................................4-1

4.2 CALCIUM POLYSULFDE..................................................................................... 4-2

4.3 SOLID AND/OR LIQUID IRON ADDITIVES ........................................................4-3

4.3.1 Micron-Sized Zero-Valent Iron Emplaced with Shear-Thinning Polymers 4-3

4.3.2 Nanoscale Zero-Valent Iron ....................................................................... 4-4

4.3.3 Iron In Solution ............................................................................................... 4-5

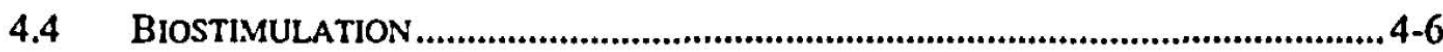

4.5 TIE POND LEAKAGE ISSUE ........................................................................4-9 
WMP-28119

Revision 0

4.6 A SUPPLEMENTAL BIOLOGICAL TREATMENT FOR THE DITHIONITE RE-INJECTION OPTION 4-9

4.7 RECOMMENDED APPROACH FOR MENDING THE BARRIER ..................................4-12

5.0 RECOMMENDATIONS FOR EXTENDING THE BARRIER ..................5-1

6.0 OTHER RECOMMENDATIONS ................................................................6.1

6.1 ALTERNATIVE DRILLING APPROACHES...........................................................6-1

6.2 WELL DEVELOPMENT/CONSTRUCTION............................................................6-1

6.3 ALTERNATIVE PH BUFFERING OF DITIIONITE SOLUTIONS ................................6-2

6.4 BARRIER OPERATIONS TO ACCOMMODATE PREFERENTIAL PATHWAYS .............6-3

7.0 SUMMARY RECOMMNDATIONS ..........................................................7-1

7.1 RECOMMENDATIONS RELATED TO UNDERSTANDLNG THE PROBLEM ....................7-1

7.2 RECOMMENDATIONS FOR MENDING THE BARRIER ............................................. 7-2

7.3 RECOMMENDATIONS FOR EXTENDING THE BARRIER ......................................... 7-3

8.0 REFERENCES................................................................................................8

APPENDIX A: TECHINICAL ASSISTANCE REQUEST ............................................ A-I APPENDIX B: IVORKSHOP ATTENDEES ......................................................... B-I APPENDIX C: AGENDA ................................................................................. C-1 APPENDIX D: BARRIER LONGEVITY AND THE NITRATE EFFECT ................. D-I

\section{LIST OF FIGURES}

FIGURE 1. EBF DATA FROM WELL D4-11 SHOW MORE THAN $40 \%$ OF THE FLOW FROM A ONE-FOOT NTERVAL (WALDROP AND PEARSON, 2002A).

FIGURE 2. EBF DATA FROM WELL D4-74 SHOWS RELATIVELY UNIFORM DISTRIBUTION OF FLW THIROUGHOUT TIE AQUIFER (FROM WALDROP AND PEARSON, 2002B).

FIGURE 3. RELATIONSHIP BETWEEN PERMEABLLITY OF HIGH-PER.MEABILITY ZONES AND OBSERVED BREAKTHROUGH OF CR(VI) (VERMELL, 2004).

FigurE 4. CONCENTRATIONS OF $\mathrm{CR}$ (VI), DO, AND $\mathrm{NO}_{3}{ }^{-}$RECORDED AT WELL 199-D4-7 FROM 1999 TIIROUGU DECEMBER 2003.

FIGURE 5. MEASURED PH AND SULFATE CONCENTRATIONS RECORDED AT INJECTION WELL 199-D4-7 VERSUS TIME.

FIGURE 6. MEASURED PH A.ND SULFATE CONCENTRATIONS RECORDED AT WELL 199-D4-1, WHICH IS DOWN-GRADIENT FROM THE TREATMENT WELL 199-D4-7.

FIGURE D-1. $\mathrm{NO}_{3}{ }^{-}$CONCENTRATIONS MEASURED IN UP-GRADIENT (199-D4-22), TREATMENT ZONE (199-D4-7), AND DOWN-GRADIENT (199-D4-1) WELLS PRIOR TO RETREATMENT OF WELL D4-7 N AUGUST 2002. 
WMP-28119

Revision 0

FIGURE D-2. COMPARISON OF $\mathrm{NO}_{3}{ }^{-}$AND NITRITE CONCENTRATIONS MEASURED AT WELL 199-D4-7 BEFORE AND AFTER TIIE SECOND SODIUM DITHIONITE INJECTION, 27AUGUST-2002.

FigURE E-1. DistribUtion OF FE ${ }^{0}$ IN A 100 -CM COLUMN OF HANFORD SEDIMENT. SLURRY COMPOSITION OF $1.0 \% \mathrm{FE}^{0}$ AND $0.5 \%$ POLYMER IN WATER. 3 PORE VOLUMES TREATMENT AT A FLOW-RATE OF $7.2 \mathrm{CM} /$ MIN AFTER A 2 PORE-VOLUME PRETREATMENT WITH $0.5 \%$ POLYMER IN WATER. E-1

FIGURE E-2. INLET BACK-PRESSURE BEFORE, DURING, AND AFTER SLURRY INJECTION......E-2

\section{LIST OF TABLES}

TABle 1. PRIORITIZATION OF TECHNOLOGIES CONSIDERED OR RECOMMENDED FOR AQuiftr CiIARActerization.........................................................................11

\section{APPENDICES}

APPENDIX A: TECHNICAL ASSISTANCE REQUEST ............................................. A-I APPENDIX B: WORKSHOP ATTENDEES .......................................................... B-I APPENDIX C: AGENDA ….................................................................................. C-I APPENDIX D: BARRIER LONGEVITY AND THE NITRATE EFFECT .................... D-I APPENDIX E: PNNL ZER0-VALENT IRON EMPLACEMENT EXPERIMENTS......E-I 
WMP-28119

Revision 0

\section{EXECUTIVE SUMMARY}

\section{Background}

In carly 2004, the U.S. Department of Energy (DOE) Richland and Fluor Hanford requested technical assistance from the DOE Headquarters EM-23 Technical Assistance Program to provide a team of technical experts to develop recommendations for mending the In Situ Redox Manipulation (ISRM) Barricr in the 100-D Area of the Hanford Site in Washington State. To accommodate this request, EM-23 provided support to convene a group of technical experts from industry, a national laboratory, and a DOE site to participate in a $2 \frac{1}{2}$-day workshop with the objective of identifying and recommending options to enhance the performance of the 100-D Area reactive barrier and of a planned extension to the northeast. This report provides written documentation of the team's findings and recommendations.

In 1995, a plume of dissolved hexavalent chromium [Cr(VI)], which resulted from operation of the D/DR Reactors at the Hanford site, was discovered along the Columbia River shoreline and in the 100-D Area. Between 1999 and 2003, a reactive barrier using the In Situ Redox Manipulation (ISRM) technology, was installed a distance of 680 meters along the river to reduce the $\mathrm{Cr}(\mathrm{VI})$ in the groundwater. The ISRM technology creates a treatment zone within the aquifer by injection of sodium dithionite, a strong reducing agent that scavenges dissolved oxygen (DO) from the aquifer and reduces ferric iron [Fe(III)], related metals, and oxy-ions. The reduction of $\mathrm{Fe}(\mathrm{III})$ to ferrous [Fe(II)] iron provides the primary reduction capacity to reduce $\mathrm{Cr}(\mathrm{VI})$ to the +3 state, which is less mobile and less toxic. Bench-scale and field-scale treatability tests were initially conducted to demonstrate proof-of principle and to provide data for estimation of barrier longevity. These calculations estimated barrier longevity in excess of twenty years. However, several years after initial and secondary treatment, groundwater in a number of wells has been found to contain elevated chromium $(\mathrm{Cr})$ concentrations, indicating some loss of reductive capacity within the aquifer.

The Technical Assistance Team (TAT) was requested to perform the following activities:

1) evaluate the most probable condition(s) that has led to the presence of $\mathrm{Cr}(\mathrm{VI})$ in 12 different barrier wells (i.e. premature loss of reductive capacity),

2) recommend methods for determining the cause of the problem,

3) recommend methods for evaluating the magnitude of the problem,

4) recommend practicable method(s) for mending the barrier that involves a longterm solution, and

5) recommend methods for extending the barrier to the northeast (e.g., changing injection procedure, changing or augmenting the injected material).

Since the March 2004 workshop, a decision has becn made to place a hold on the barrier extension until more is known about the cause of the problem. However, the report complies with the original request for information on all of the above activities, but focuses on determining the cause of the problem and mending of the existing barrier. 
WMP-28119

Revision 0

Most Probable Conditions for Premature Loss of Reductive Capacity

The TAT recognizes that the actual cause of premature breakdown in reductive capacity of the aquifer in the 100-D Area is unknown; however, they believe that the primary causes are: 1) physical and chemical heterogeneity within the aquifer and 2) the presence of other oxidants, such as nitrate, which were not recognized in the earliest predictions of barrier longevity.

Preferential pathways within the aquifer have recently been identified through hydraulic conductivity measurements using the Electronic Borehole Flowmeter (EBF).

Groundwater flowing through these pathways likely flushes large quantities of oxic water rapidly through the treatment zone, rapidly reducing its reductive capacity and the estimates of barrier longevity. In addition to flushing with high volumes of groundwater, these preferential pathways are also likely to be deficient in reactive iron, again limiting the reductive capacity of the barrier and the performance of the dithionite lixiviant.

The TAT believes that the lack of performance of the barrier at a few specific locations does not invalidate the ISRM approach. The majority of the barrier appears to be performing according to expectations. Problems with the barrier appear to be associated with preferential pathways that were not sufficiently identified or considered during design and construction of the barrier. In addition, expectations for barrier longevity were probably too high, as calculations did not take into account the presence of other oxidants in the groundwater that would utilize the majority of the reductant introduced into the subsurface.

Recommendations for Determining the Cause of the Problem

The TAT recommends conduct of an aquifer characterization study to improve the sitespecific understanding of the physical and chemical heterogeneity of the aquifer along the location of the existing barrier. The aquifer characterization study goal should be to improve understanding of depth-discrete variability in physical parameters, such as hydraulic conductivity, and chemical parameters, such as chemistry of both groundwater and aquifer media, with particular emphasis on quantity and distribution of reactive iron and other oxidants that may impact the performance of ISRM.

The TAT identified and evaluated a number of technologies and tools to perform the recommended aquifer characterization study. Minimum requirements for aquifer characterization include application of the following tools:

1) continuous cores with depth-discrete sampling for physical and chemical analyses in new boreholes located near wells showing breakthrough,

2) borehole geophysical logs (neutron-neutron and natural gamma) in all existing wells and new boreholes, and

3) EBF measurements in all existing wells and new boreholes.

In addition, tracer and hydraulic tests should be applied on a limited basis to provide fluid-flow information that can be used to design the mending approach and to enhance the robustness of the conceptual model. 
The TAT recommends the following approach to aquifer characterization:

1) conduct geophysical logging and perform EBF measurements in all existing wells;

2) utilize the data collected in \#1 and all prior data to construct a 3-D conceptual model detailing geology, hydrology, and chemistry (groundwater and aquifer materials) along the existing barrier;

3) utilize the conceptual model to target locations for drilling of new borcholes for collection of depth-discretc information; new boreholes shall be located near existing wells showing breakthrough;

4) conduct detailed depth-discrete characterization by drilling of new boreholes;

5) refine the conceptual model based upon the newly collected data, including creation of two-dimensional and three-dimensional visualizations; and

6) utilize the refined conceptual model to design bench-scale tests for mending of the existing barricr.

Additional characterization tools described in the report (e.g., cross-borehole geophysics, flux testing, FLUTe conductivity profiler) should be considered on a limited basis to further understanding of aquifer heterogeneity and hydraulics, depending upon budget available for the aquifer investigation. Because no budget or site-specific costs for an investigation were provided. the TAT could not make specific recommendations regarding a detailed scope for the investigation. Instead, the team ranked the technologies as to high, medium, and low priority. All high-priority technologies are required, as a minimum, for the investigation. The medium-priority technologies are recommended for deployment on a limited basis.

\section{Recommendations for Evaluating the Magnitude of the Problem}

Because there is insufficient knowledge of the chemical and physical heterogeneity in the aquifer along the length of the existing barrier, it is difficult to assess the magnitude of the problem. In order to understand the magnitude of the problem, it will be necessary to develop and refine a conceptual model of the aquifer based upon 1) data obtained from the recommended aquifer characterization study as well as 2) existing data. After conduct of the aquifer characterization study and refinement of the conceptual model, the magnitude of the heterogencity and the extent of the preferential pathways will provide some basis for understanding the magnitude of the problem, allowing prediction of future conditions.

\section{Recommendations for Mending the Barrier}

The TAT recognizes that the results of the aquifer characterization study must be utilized to further evaluate and select barrier-mending options. The TAT fully believes that the barrier can be successfully mended based upon an improved understanding of aquifer heterogeneity. Mending options, which include chemical and biological reductants utilizing the existing barrier wells, must be further evaluated to determine viability based upon performance, including long-term performance, and cost criteria. Those that pass the viability evaluation must be bench-scale tested to obtain a side-by-side comparison of performance, including estimation of long-term performance. The preferred option will likely require pilot field-testing prior to broad application. The use of the existing barrier wells to deliver chemical treatment materials to the subsurface will enable a cost- 
WMP-28119

Revision 0

effective approach to solving the problem. It is highly likely that the recommended approach will consist of a combination of options applied as a treatment system.

The evaluation of barrier-mending options should compare the baseline of sodium dithionite re-injection to alternatives such as iron, calcium polysulfide, and biostimulation and should consider combinations of those various treatment alternatives.

One of the major questions to be answered by the aquifer characterization study is whether the aquifer contains sufficient reactive iron throughout its vertical extent to enable long-term performance of the sodium-dithionite option. If the aquifer is shown to contain intervals deficient in reactive iron, the TAT recommends 1) direct addition of iron (solid or liquid) either alone or in combination with dithionite, 2) direct addition of calcium polysulfide (does not require iron in the aquifer), or 3) application of amendments to promote biological reduction, either alone or more likely with some combination of the previous alternatives. These options should all be investigated further for application through the existing injection-well system. In addition, the TAT recommends consideration of biological amendments up-gradient of the barrier to remove the other oxidants, such as nitrate, that are utilizing significant quantities of the lixiviant within the treatment zone.

The TAT recommends that the 182-D Reservoir either be taken out of service or lined as seepage through the floor of the basin likely impacts the existing barrier and would have an even greater impact on the proposed barrier extension. The hydraulic head created by this reservoir is believed to enhance rapid flushing of the treatment zone with untreated water containing significant oxidants, reducing its reductive capacity.

\section{Recommendations for Extending the Barrier}

For barrier extension, all of the above recommendations pertain. Before the extension can be designed, the aquifer must first be characterized to provide depth-discrete information on physical and chemical heterogeneity in order to design the well locations and amendment application procedures. If the character of the aquifer in the vicinity of the proposed extension is similar to that at the existing barrier, the bench-scale testing conducted for the barrier mending should be appropriately applied to design of the extension. If significant differences exist, it may be necessary to conduct some benchscale testing with site-specific aquifer materials.

The TAT also provides recommendations regarding well drilling and installation, with particular emphasis on well development. It is possible that many of the existing wells were not sufficiently developed to remove formation damage due to drilling. This could be affecting the performance of the existing barrier and can easily be remedied through a more effective well-development procedure. Alternative drilling methods should be considered to reduce costs.

The TAT recommends consideration of biological sulfate reduction as a supplement to the chemical reduction described under mending options. Because injection operations for the barrier extension have been modified to delete the final step of groundwater extraction after injection, high concentrations of sulfate will remain in the aquifer after 
WMP-28119

Revision 0

lixiviant injection. The high concentrations of sulfate could be utilized to increase the reductive capacity of the barrier through enhancement of sulfate-reducing bacteria. If mending of the barrier is conducted using the same injection plan as for the barrier extension, the same recommendation applies.

The overall approach for extending the barrier should utilize all the lessons learned from the mending of the barrier, including detailed aquifer characterization and testing of mending alternatives, if deemed necessary. 
WMP-28119

Revision 0

\subsection{INTRODUCTION}

\subsection{Technical Assistance Request}

In early 2004, the U.S. Department of Energy (DOE) Richland and Fluor Hanford requested technical assistance from the DOE Headquarters EM-23 Technical Assistance Program to provide a team of technical experts to develop recommendations for mending the In Situ Redox Manipulation (ISRM) Barrier in the 100-D Area of the Hanford Site in Washington State. Appendix A contains the original technical assistance request.

To accommodate this request, EM-23 provided support to convene a group of technical experts to participate in a $2 \frac{1}{2}$-day workshop with the objective of identifying and recommending options to enhance the performance of the 100-D Area reactive barrier and of a planned extension to the northeast. A number of technical experts from industry, a national laboratory, and a DOE site were identified as technical assistance team (TAT) participants with expertise in aqueous geochemistry, hydrogeology, permeable reactive barriers and other in situ remediation technologies, and aquifer characterization technologies. Appendix B provides contact information for the technical assistance team members and other attending the workshop on March 2, 2004.

\subsection{Site History, the Problem, and the Remedial Alternative}

From 1944 through 1967, operation of the D/DR Reactors at the Hanford Site utilized large volumes of Columbia River water to cool the reactors. To protect the reactor equipment, sodium dichromate-dihydrate was added to the cooling water to inhibit corrosion. The geometry of the current groundwater plume suggests that the release(s) occurred near the facility where water was treated before it was used in the reactors. The actual source location has not been confirmed, but it is known that chromate-rich water leaked into the soil and contaminated the groundwater. In 1995, a plume of dissolved hexavalent chromium $[\mathrm{Cr}(\mathrm{VI})]$ was discovered along the Columbia River shoreline and in the 100-D Area. In 1997, a treatability test was implemented in one well in the 100-H Area to test ISRM as an in situ treatment solution for this problem. In 1998, a second demonstration of the ISRM concept using five wells in the 100-D Area was conducted. In 1999, the Record of Decision for this operable unit, 100-HR-3, was modified to select ISRM as the altemative for the 100-D/DR plume. In three phases between 1999 and 2003 , the ISRM barrier was extended to its current length of 680 meters, producing a zone of reduction designed to intercept and reduce $\mathrm{Cr}(\mathrm{VI})$ in the groundwater before it reaches the Columbia River.

\subsection{ISRM Methodology and Performance}

The ISRM technology involves creation of a treatment zone within the aquifer by injection of sodium dithionite, a strong reducing agent that scavenges dissolved oxygen (DO) from the aquifer and reduces ferric iron [Fe(III)], related metals, and oxy-ions. The reduction of $\mathrm{Fe}$ (III) to ferrous [ $\mathrm{Fe}$ (II)] iron provides the primary reduction capacity to treat $\mathrm{Cr}(\mathrm{VI})$ ions flowing through the treatment zone. Chromium $(\mathrm{Cr})$ is removed from 
WMP-28119

Revision 0

the groundwater as it flows into and through the treatment zone, being reduced from the mobilc hexavalent state $[\mathrm{Cr}(\mathrm{VI})]$ to the relatively immobile trivalent state $[\mathrm{Cr}(\mathrm{III})]$.

To emplace the reductive barrier, a linear scrics of boreholes were drilled into the aquifer to create a treatment zone that intercepts the groundwater plume. A liquid solution of sodium dithionite was injected into these wells. After allowing approximately 36 hours for reaction, residual reagent and byproducts were extracted from the aquifer. As contaminated groundwater passed through the treated zone, ferrous iron in the formation reduced the mobile and toxic $\mathrm{Cr}(\mathrm{VI})$ to $\mathrm{Cr}(\mathrm{III})$, which is much less toxic and significantly less mobile in groundwater.

Before the barrier was emplaced, field and laboratory tests were undertaken to evaluate the feasibility of this technology and to predict the longevity of the treatment zone. The tests indicated that the barrier should maintain its reductive capacity for approximately 20 years. However, less than three years after emplacement, chromium concentrations in some of the five initial treatability-test wells increased, indicating that the treated aquifer may be losing its reductive capacity. In 2002, these five wells were reinjected with sodium dithionite to reestablish reductive capacity in the aquifer at these locations. Since then, chromium has been detected in six more wells, again indicating premature loss of reductive capacity in the aquifer.

Results of the January 2004 monitoring provided to the TAT revealed that the ISRM barrier has failed at six locations: 1) at four locations in the eastem portion of the barrier near wells a) D4-37, D4-40, and D4-41, b) D4-21 and D4-8, c) D4-31, and d) D4-25, D426 , and D4-27; 2) in two locations in the western portion of the barrier near well a) D4-56 and b) D4-65.

The longevity of the treatment zone is dependent upon:

- quantity and distribution of residual $\mathrm{Fe}(\mathrm{II})$ throughout the aquifer,

- flow rate of untreated groundwater through each discrete interval of the treatment zonc, and

- concentrations of oxidizing constituents in the incoming groundwater through each interval in the aquifer.

The original prediction of barrier longevity was based upon average values for each of these parameters, assuming a relatively homogeneous aquifer.

Plans originally made to extend the barrier 600 meters to the northeast to complete the capture of the plume are currently on hold.

\subsection{Technical Assistance Objectives And Methodology}

Workshop objectives provided to the TAT by DOE Richland and Fluor Hanford includes:

1) evaluate the most probable condition(s) that has led to the presence of $\mathrm{Cr}(\mathrm{VI})$ in 12 different barrier wells (i.e. premature loss of reductive capacity);

2) recommend methods for determining the cause of the problem; 
WMP-28119

Revision 0

3) recommend methods for evaluating the magnitude of the problem;

4) recommend practicable method(s) for mending the barrier that involves a longterm solution (may likely involve alternative chemical or biological reductants); and

5) recommend methods for extending the barrier to the northeast (c.g., changing injection procedure, changing or augmenting the injected material).

The TAT was convened in Richland, Washington to participate in a technical workshop March 2-4, 2004. The workshop agenda is provided in Appendix C. On the morning of the first day, presentations on historical operations and the current situation were made by a number of staff from the Pacific Northwest National Laboratory (PNNL) and Fluor Hanford. In the afternoon of the first day, the TAT attended a site tour led by PNNL and Fluor Hanford staff. After this assessment of the current situation, the TAT began discussions related to items \#1 through 5 above. Immediately prior to the end of the workshop, the TAT provided an out-briefing of their preliminary findings and recommendations. After the workshop, the TAT prepared this report to document the recommendations of the team and the results of the workshop. The remainder of the report focuses on the workshop objectives described above, \#1-5. The major emphasis is on providing findings of the probable cause of the problem and recommendations for: 1) determining cause(s) of the premature breakdown and magnitude of the problem, 2) mending the barrier, and 3 ) extending the barrier. 
This page intentionally left blank

WMP-28119

Revision 0

\section{Revision 0}

This page intencionally left blank

$1-4$


WMP-28119

Revision 0

\subsection{POTENTIAL CAUSES OF THE PROBLEM}

The TAT recognizes that the actual cause of premature breakdown in reductive capacity of the aquifer in the 100-D Area is unknown. A list of potential causes was provided by Fluor Hanford to be considered by the TAT:

- heterogeneity (rc-oxygenation within high-flow velocity zones);

- variability in reduced iron content and other geochemical indicators, i.e., chemical heterogeneity;

- fluctuating water table (oxygenation from water-level decline);

- re-oxygenation of reduced zone during air rotary drilling;

- formation disturbance (fracturing) / trapped air from air-rotary drilling; and,

- natural re-oxygenation rates (dissolved oxygen [DO] content in the natural groundwater).

The TAT revicwed the list of potential causes and tried to identify additional causes. The only additional potential cause identified by the TAT was:

- presence of significant quantities of oxidants other than $\operatorname{Cr}(\mathrm{VI})$ in the aquifer.

The TAT discussed all of the above potential causes of the problem and reviewed raw data and some written reports. It was recognized by the TAT that site-specific aquifer characterization data available during design of the barrier were extremely limited. Current aquifer characterization data provided to the TAT indicated that heterogeneity may be a significant issue.

The TAT has concluded that the primary cause of premature breakdown in reductive capacity of the aquifer is the geologic, geochemical, and hydrologic heterogeneity within the aquifer. The heterogeneity is likely to be chemical (e.g., variability in reduced iron content) and physical (high-flow velocity intervals that are flushed with untreated groundwater). Heterogeneities within the aquifer create preferential pathways that allow rapid groundwater movement through the barrier in discrete intervals not predicted using the homogencous aquifer model. These aquifer heterogeneitics and their impacts on the ISRM system are described in the following sections, along with some discussion of the other potential causes listed above. In addition, the TAT also believes that the presence of oxidants other than $\mathrm{Cr}(\mathrm{VI})$ in the groundwater contributes significantly to the problem.

\subsection{Physical Heterogeneity}

Evidence for physical heterogeneity was provided by: 1) relative hydraulic conductivity data measured using the Electronic Borehole Flowmeter [EBF] (Waldrop and Pearson, 2002a and b) and 2) examination of core photographs (Appendix GG, FY2002 Annual Summary Report for the ISRM Operations, DOE/RL-2003-05). The examination of the core photographs revealed differences in redox properties of the aquifer along the vertical extent of the cores. For example, cores obtained from the vicinity of well D4-7 showed highly oxic conditions (low reductive capacity) at approximately 90.5 feet bgs. 
The EBF results showed heterogeneous flow within depth-discrete intervals in some wells where more than forty percent of the flow was present within a one-foot interval in one well (Figure 1), while other wells showed a relatively homogeneous distribution of hydraulic conductivity throughout the 15-foot screened interval (Figure 2). Hydraulic conductivities within the aquifer appear to vary orders of magnitude on a foot-by-foot basis. At locations where significant heterogeneity was measured, higher hydraulic conductivitics were generally found towards the top of the aquifer. It is not clear at this point in time, whether all of this heterogeneity is real or whether some may be an artifact of well drilling and development procedures. It is possible that well development towards the base of the screens was not performed sufficiently to reduce formation damage. Results from the aquifer characterization study may help to answer this question. 


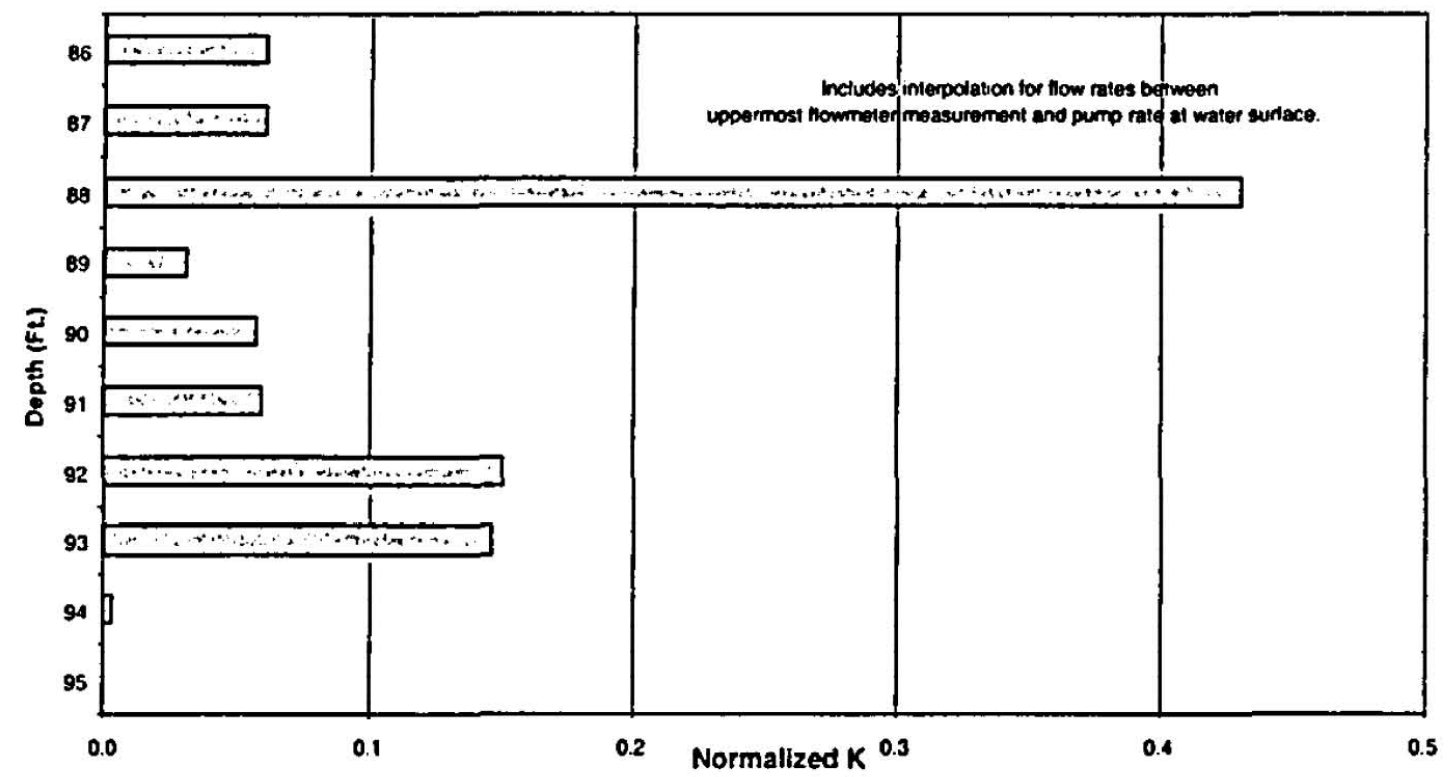

Figure 1. EBF data from Well D4-11 show more than $40 \%$ of the flow from a onefoot interval (Waldrop and Pearson, 2002a).

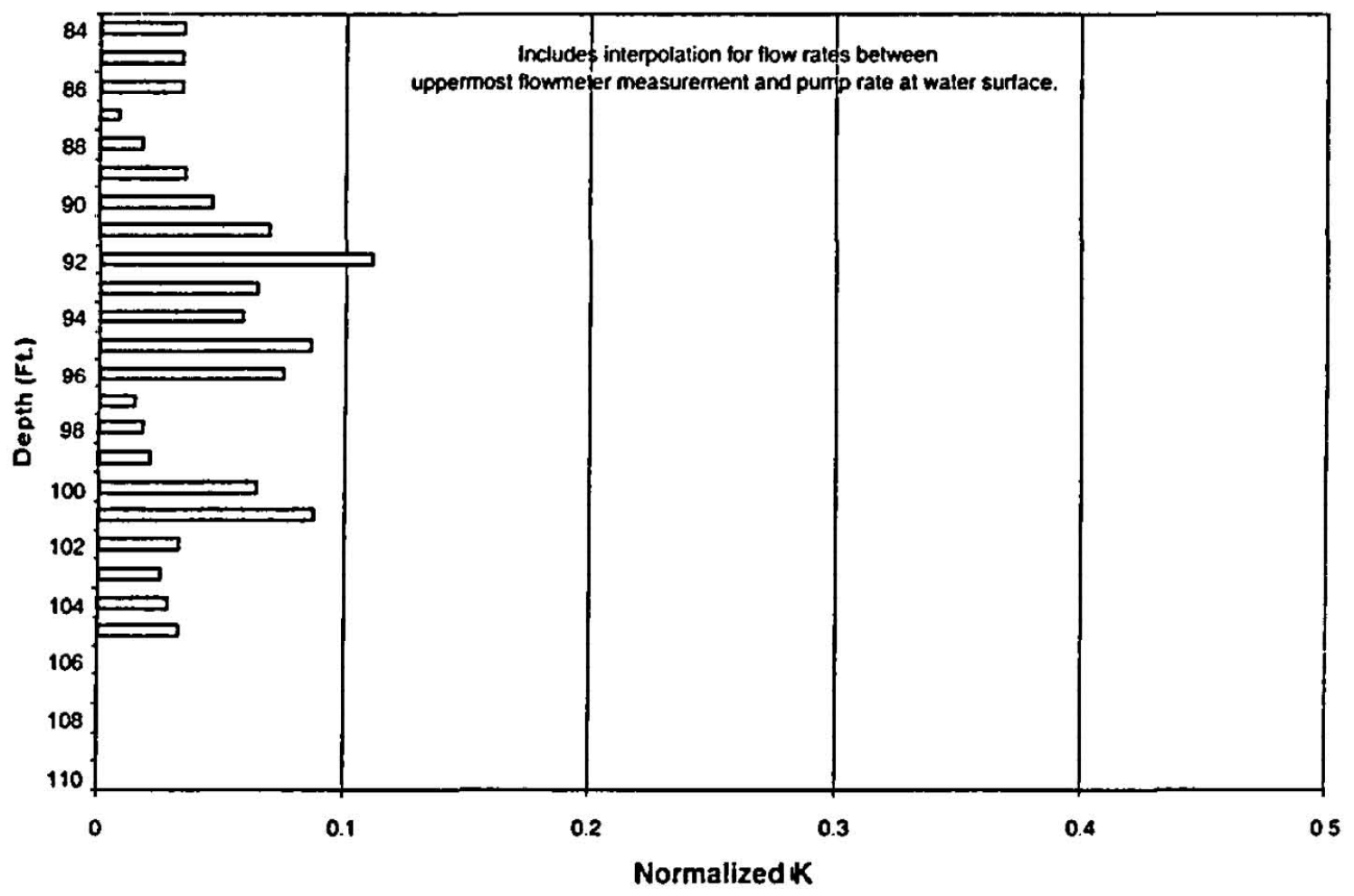

Figure 2. EBF data from Well D4-74 shows relatively uniform distribution of flow throughout the aquifer (from Waldrop and Pearson, 2002b). 
WMP-28119

Revision 0

\subsection{Chemical Heterogeneity}

Detailed data on chemical variability with depth in cores were either not available or were not provided to the team, given time constraints. Howcver, the preferential pathways where high-flow conditions exist are also likely to contain lesser quantities of iron, either due to 1) less reactive iron due to less available surface area due to the coarser grain-size, or 2) flushing of the high-permeability zones with significant quantities of oxic water, reducing the amount of available $\mathrm{Fe}(\mathrm{III})$ in the aquifer required for the dithionite reduction process to be effective.

In many sedimentary units, native $\mathrm{Fe}$ (III) concentrations are lower in high-permeability zones than in low-permcability intervals. It is commonly believed that groundwater preferentially flows through the high-permeability zones, which can result in removal of iron at a higher rate than in lower permeability zones. A well-studied example of this phenomenon is the Navajo Sandstone Formation in the Colorado Plateau geologic province; the Navajo Sandstone has widespread permeable zones that are bleached to a tan or white color due to removal of iron by groundwater, interbeded with red-colored (iron-rich) finer-grained units.

It is possible that during and after injection of dithionite, continued preferential groundwater flow further depleted these intervals of iron. ISRM effectiveness may be limited within the preferential pathways because of limited available iron and because of higher groundwater velocities.

The direct relationship between relative permeability in the high-permeability zones and the observed $\mathrm{Cr}$ breakthrough (Figure 3 ) provides additional support for the hypothesis that preferential pathways with limited available iron are controlling performance of the ISRM barricr. 
WMP-28119

Revision 0

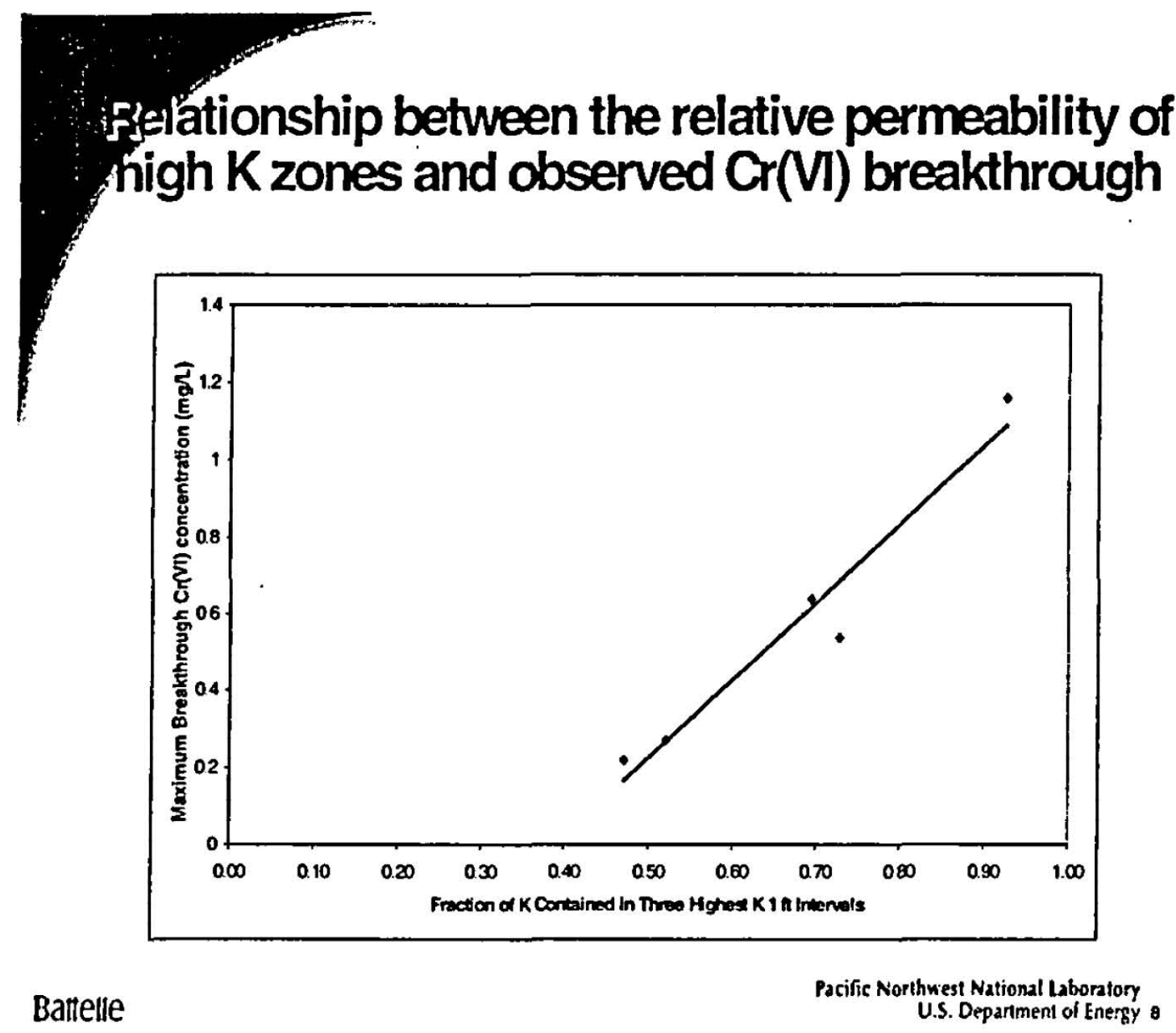

Figure 3. Relationship between permeability of high-permeability zones and observed breakthrough of $\mathrm{Cr}(\mathrm{VI})$ (Vermeul, 2004). 
WMP-28119

Revision 0

\subsection{Other Oxidants}

The presence of significant quantities of oxidants other than $\mathrm{Cr}(\mathrm{VI})$, such as oxygen $\left(\mathrm{O}_{2}\right)$ and nitrate $\left(\mathrm{NO}_{3}{ }^{-}\right)$, in the groundwater at Hanford has likely impacted the performance of dithionite as a reductant in the aquifer, in terms of barrier longevity. Calculations of barrier longevity did not originally include the effect of the $\mathrm{NO}_{3}^{-}$. Observations of barrier breakthrough that include $\mathrm{Cr}(\mathrm{VI}), \mathrm{DO}$, and $\mathrm{NO}_{3}{ }^{\circ}$ show similar trends over time (Figure 4), inferring that $\mathrm{O}_{2}, \mathrm{NO}_{3}{ }^{-}$and $\mathrm{Cr}(\mathrm{VI})$ in the groundwater are all controlled by the same mechanism. This suggests competition between $\mathrm{NO}_{3}{ }^{-}$and $\mathrm{Cr}(\mathrm{VI})$ for $\mathrm{Fe}(\mathrm{II})$ as the reductant. The importance of the effect of $\mathrm{NO}_{3}{ }^{-}$and $\mathrm{O}_{2}$ must be considered in the longevity calculations. More recent calculations including the effects of $60 \mathrm{mg} / 1 \mathrm{NO}_{3}$. and $5.1 \mathrm{mg} / \mathrm{O} \mathrm{O}_{2}$ show a 10-year longevity (Szecsody, 2004).

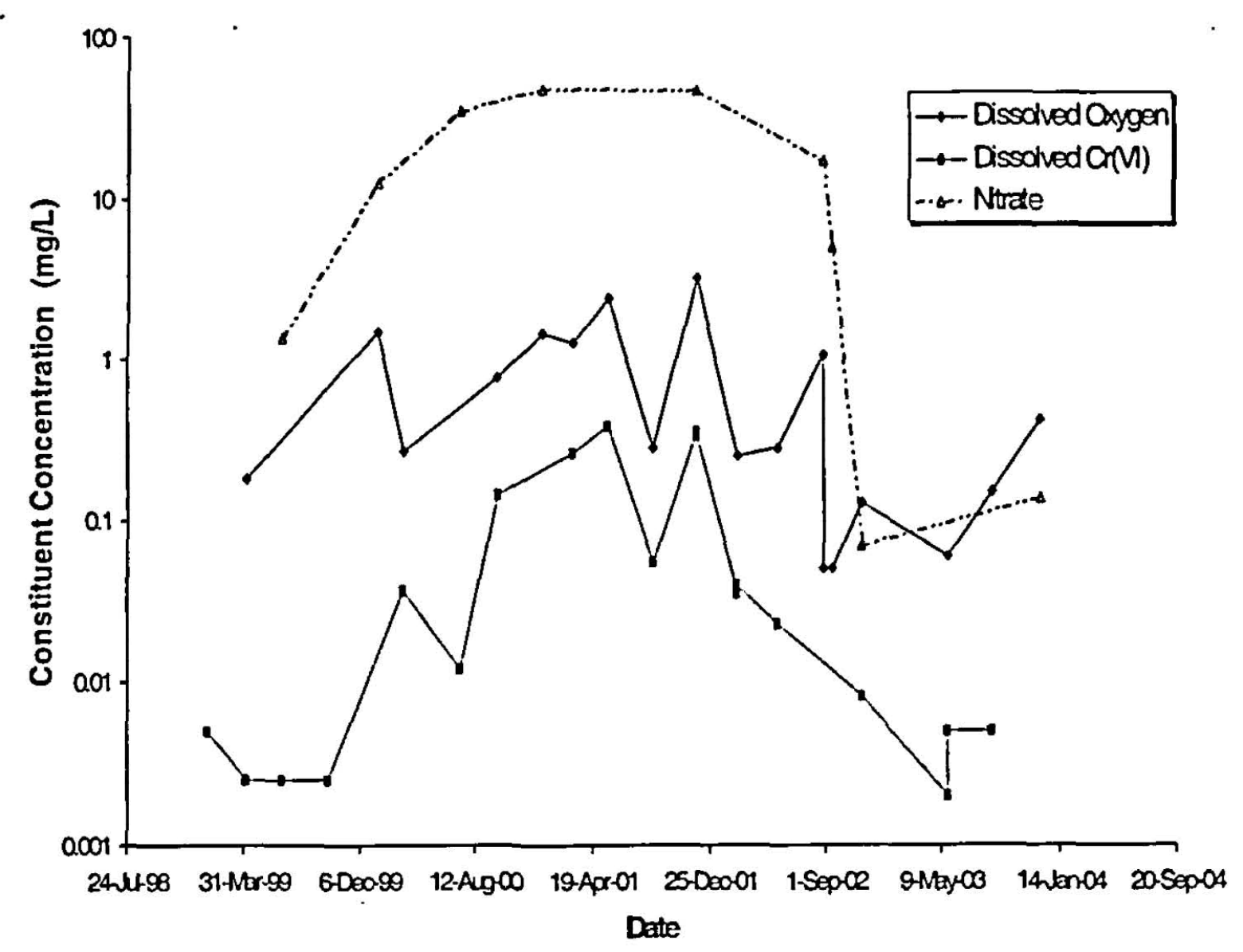

Figure 4. Concentrations of $\mathrm{Cr}(\mathrm{VI}), \mathrm{DO}$, and $\mathrm{NO}_{3}{ }^{-}$recorded at well 199-D4-7 from 1999 through December 2003.

More specifics about the fate of $\mathrm{NO}_{3}{ }^{-}$, within the barrier are described in Appendix D. A concomitant increase in nitrite indicates that at least a portion of the $\mathrm{NO}_{3}{ }^{-}$, was converted to nitrite (Appendix D). However, the increase in nitrite on a molar basis is only a 
WMP-28119

Revision 0

fraction of the amount of $\mathrm{NO}_{3}{ }^{-}$removed, suggesting that the $\mathrm{NO}_{3}{ }^{-}$may be transformed to more reduced phases, such as nitrogen gas or ammonia, using up even more reductive capacity within the aquifer.

If the $\mathrm{Fe}$ (II) in the treatment zone were oxidized only by $\mathrm{O}_{2}$ and $\mathrm{Cr}(\mathrm{VI})$, assuming concentrations of $8.4 \mathrm{mg} / \mathrm{L}$ and $1.29 \mathrm{mg} / \mathrm{L}$ respectively, approximately $6.6 \%$ of the reducing equivalents in the barrier are consumed by $\mathrm{Cr}(\mathrm{VI})$ and the remaining $93.4 \%$ by $\mathrm{O}_{2}$. When considering the additional $\mathrm{NO}_{3}{ }^{-}$present in the groundwater ( 60 to $70 \mathrm{mg} / \mathrm{liter}$ ), which is another oxidized species targeted by the reductant, the quantity of reducing equivalents that reach $\mathrm{Cr}(\mathrm{VI})$ could bc as little as $0.8 \%$ to $2.5 \%$, depending on the degree of $\mathrm{NO}_{3}{ }^{-}$reduction, with $>97 \%$ of the reducing power of the barrier being consumed by non-target constituents.

The potential effect of $\mathrm{NO}_{3}{ }^{-}$and $\mathrm{O}_{2}$ on barrier longevity is likely to be exacerbated by physical heterogeneities that result in a greater mass flux of oxidants through a limited cross-sectional area over unit time.

\subsection{Other Possible Causes}

Even though the effect of river stage on the aquifer has hydrologic significance, the TAT does not believe that the fluctuating water table, due to changes in river stage, could be the primary cause of loss of reductive capacity in the barrier. The amount of $\mathrm{O}_{2}$ introduced by water-level changes should primarily impact the upper portion of the aquifer; river stage may have some effect on barricr performance, but it is likely not sufficient to be a significant factor in the barrier breakthrough.

Air-rotary drilling of injection and monitoring wells may have produced some oxidation of the aquifer, but the TAT believes air-rotary drilling would not have produced the observed conditions. Evidence for this conclusion includes the fact that there is not a direct correlation between wells that have premature breakdown and the type of drilling. Many wells installed by air-rotary methods have shown premature breakdown, but some wells with premature breakdown were installed with cable tool and some air rotary wells have not experienced breakdown.

\subsection{Summary of Possible Causes}

In summary, the TAT believes that the primary causes of the premature breakdown in reductive capacity are: 1) both physical and chemical aquifer heterogeneity, which creates preferential pathways for the migration of fluids in the subsurface and affects the reductive capacity of the aquifer, and 2) the presence of significant quantities of other oxidants, namely $\mathrm{NO}_{3}{ }^{\circ}$, which have affected the reductive capacity of the treated aquifer. When considering the three factors that determine barrier longevity, as described in section 1.3, all are likely to contribute to the problem (lack of ferrous iron in some intervals, high flow rates through preferential pathways, and presence of competing oxidants). 
The TAT, however, does not believe that the lack of full barrier performance invalidates the ISRM approach. The majority of the barrier is performing per expectations. Barrier breakthrough appears to be associated with preferential pathways that were not sufficiently identified or considered during barrier design, construction, and longevity predictions. The TAT believes that mending of the barrier can be accomplished after a better understanding of the cause and magnitude of the problem has been obtained by the aquifer characterization investigation. The TAT also recommends that the existing barrier be mended and results evaluated prior to construction of the barrier extension. This is in concert with a decision that has been made since March 2004.

\subsection{Magnitude of the Problem}

The recommendations that are made concerning understanding the cause of the problem coupled with modeling should be used to address the magnitude of the problem. At present, there is not sufficient data to address this issue. After the investigation of aquifer heterogeneity is completed, the magnitude of the problem can be better assessed. Data collected during the aquifer characterization investigation, can be incorporated into 1) 2 $\mathrm{D}$ and/or 3-D flow and transport models to predict average down-gradient $\mathrm{Cr}(\mathrm{VI})$ concentrations, and/or 2) a reasonably simple spreadsheet set up to calculate chemical mass balance and flux and what the average down-gradient $\mathrm{Cr}(\mathrm{VI})$ concentration should be. Comparison of these values to regulatory targets will enable better determination of the magnitude of the problem. 
WMP-28119

Revision 0

\subsection{RECOMMENDATIONS FOR IMPROVED UNDERSTANDING OF THE PROBLEM (CAUSE AND MAGNITUDE)}

As part of the technical assistance request, the TAT was charged with providing recommendations of field and laboratory methods that could be implemented to improve the understanding of the premature breakdown and potential magnitude of the problem. The TAT believes it is critical to perform a detailed aquifer characterization study to better understand the physical and chemical heterogeneity of the aquifer, the potential cause of the brcakdown of barrier performance, thus enabling predictions as to the magnitude of the problem to be made.

The TAT considered a number of field methods that would provide significant depthdiscrete data related to geologic and hydrologic parameters. An improved understanding of the lateral and vertical variability in aquifer materials can be obtained by collection of depth-discrete data within the area of the existing barrier. Use of multiple tools to obtain various types of hydrogeologic data, which can be integrated to develop a robust understanding of the heterogeneity of the aquifer as depicted in a 3-dimensional conceptual model, is recommended. The following list of field methods is not allinclusive, but represents those discussed by the team given limited time available.

The TAT identificd a number of potential technologies and approaches and then evaluated those in terms of performance/effectiveness and relative cost to develop recommendations for an investigation that can be targeted to obtaining a better understanding of the aquifer lateral and vertical heterogeneity. The technologies considered and described in order of priority (as recommended by the TAT) in the following sections include the following:

- depth-discrete core analysis (physical and chemical parameters)

- borehole geophysics

- Electronic Borchole Flowmeter

- tracer tests

- hydraulic tests

- modcling

- cross-boreholc geophysics

- flux testing

- FLUTe hydraulic conductivity profiling

- surface geophysics.

In the following sections, each of the technologies is described in terms of applicability to provide information on aquifer heterogeneity. The TAT recommends the use of a select group of the above technologies to conduct a cost-effective hydrogeologic characterization program along the existing barrier to identify the existence and extent of preferential pathways and to improve overall understanding of the problem. 
WMP-28119

Revision 0

The overall goal of the aquifer characterization will be to develop and refine a conceptual model of the aguifer in order to understand causes of the problem, predict the magnitude of the problem, and design methods for mending and/or extending the barrier. The conceptual model should include a 3-D visualization of geologic, hydrologic, and chemical heterogencity along the extent of the existing barrier. Well construction information should be overlain on the hydrogeology and chemistry.

The TAT recommends that geophysical logs and EBF measurements be first made in all existing wells. These new data and existing other data should be used to construct the initial conceptual model, which then can be utilized to select appropriate locations for new borings to complete the aquifer characterization investigation. Locations near wells showing breakthrough should be targeted for further investigation.

The TAT recommends a comprehensive analysis using all existing and newly collected data, portrayed in three-dimensional and two-dimensional visualizations to improve understanding of heterogeneities both laterally and vertically within the aquifer and the potential effects on barrier effectiveness. This will enable interpretation of the cause of the problem and its magnitude and will enable specific recommendations for mending the barrier.

\subsection{Depth-Discrete Core Analysis}

Geologic information that can be gained from the construction of injection or monitoring wells using reverse air rotary or cable tool methods is limited mostly to analysis of cuttings. The cuttings from cable-tool drilling represent a mix of that material penctrated since the last depth the well was bailed. Core samples provide significant additional information, but duc to the expense were not collected continuously in every well. Prior to the initial treatability test in 1999 and in 2002 after the dithionite injection, more detailed analyses were performed using limited core from three boreholes. Many of the recommendations below follow the procedures utilized for those core samples. The major difference is that we recommend more closely spaced depth-discrete sampling and robust analysis using multiple data sets to produce a geospatial visualization, so that a better understanding of preferential pathways and their vertical extent can be obtained.

The TAT recommends a detailed analysis of multiple depth-discrete core samples along the existing barrier and in some percentage of the planned injection wells along the barrier extension to assess the presence of preferential-flow channels in highpermeability strata as well as to understand the depth-specific distribution of reactive iron [Fe(II)], sulfur, and $\mathrm{Cr}$. The objective of the core study is to delineate both physical and chemical heterogeneity both laterally and vertically. Core data can also be used to quantify the mass of $\mathrm{Cr}$ that has been deposited in the barrier and to evaluate the relationship between $\mathrm{Cr}$ and iron. The depth-specific core data can be correlated with other hydrogeologic characterization data, e.g., EBF and borehole geophysics, for improved understanding of the location and characteristics of the permeable horizons. A quantitative understanding of the physical and chemical heterogeneities in the formation 
WMP-28119

Revision 0

will help identify the primary reasons for barrier breakthrough and will be eventually factored into re-designing the injection strategy for mending and extending the barrier.

\subsection{Borehole Geophysics}

Borehole geophysics offers a cost-effective technique to obtain continuous-depth, in-situ geologic and associated hydraulic information both in existing injection and monitoring wells and in new boreholes to be constructed. Two borehole geophysical techniques offer the greatest potential for collection of information within cased and uncased boreholes on the presence or absence of preferential pathways: 1) neutron-neutron logging, and 2) natural gamma logging.

Neutron-neutron logging is a well-established technique for in-situ determination of formation porosity below the water table. The technique involves raising or lowering a tool that contains a radioactive (neutron emitting) source and an epithermal neutron detector unit. The resultant log allows identification of lithologic changes based on porosity differences.

Natural gamma logging is also a well-established technique for subsurface characterization within either cased or uncased boreholes. The technique involves raising or lowering a tool that contains a gamma detector. Because clay generally has the highest gamma-emission characteristics of natural material, the gamma log allows identification of depth-discrete clay-rich zones.

Integrated analysis of data from neutron-neutron and natural gamma logs within a single borehole enables identification of high-porosity zones with low clay content, which should be high hydraulic-conductivity zones (i.e. preferential pathways). Borehole geophysical logs should also be correlated to geologic descriptions from cores to groundtruth the measurements. Correlation of the logs between wells will allow construction of a hydrogeologic conceptual model that can identify the presence and extent, both vertically and laterally, of preferential pathways.

The TAT recommends that borehole geophysical logging be conducted in all boreholes drilled to investigate the cause of the problem along the barrier, in all existing wells, and in all future wells, such as the barrier-extension wells. Significant resources should be dedicated to interpretation of these data and integration with other existing data and data planned for collection.

\subsection{Electronic Borehole Flowmeter Measurements}

Dynamic flow-meter logging provides a method to identify high hydraulic conductivity zones within the perforated interval of a completed well. An electromagnetic borehole flowmeter (EBF), developed by Quantum Engineering Corporation, has been successfully used in a selected number of barrier wells (25) in the 100-D Area of the Hanford Site. Depth-discrete flow measurements were made under dynamic conditions within these wells. Calculations of relative hydraulic conductivity were then completed 
WMP-28119

Revision 0

for each measurement point within the borehole. The EBF data have provided very useful information, depicting that some borcholes contain thin, high hydraulicconductivity zones, whereas other boreholes demonstrate a relatively homogeneous aquifer. As previously mentioned, data from some wells have demonstrated more than fifty percent of the flow within a one-foot interval in the fifteen-foot thick aquifer.

The TAT has not had direct experience with the EBF method. However, based upon the results presented by PNNL staff, the method appears to provide very useful information on quantifying the vertical heterogeneity of the aquifer.

The TAT recommends that the existing EBF data be analyzed with the goal of creating a three-dimensional image of potential preferential pathways in the treatment zone. This interpretation can then be utilized to design an investigation to better characterize preferential pathways along the barrier.

The TAT also recommends that EBF measurements be made in 1) all existing wells, 2) all boreholes installed to investigate the cause of the problem in the existing barrier and 3) all future wells to improve understanding of aquifer heterogeneity. EBF data should be collected immediately after drilling to assess whether special well completion or injection operations may be required in some of the injection wells. An attempt should be made to collect depth-discrete groundwater data for $C r$ analysis in concert with the EBF measurements so that calculation of $\mathrm{Cr}$ flux can be made. A sampling attachment to the flowmeter should be constructed. Cr flux information would be very useful in the design of the barrier mending.

\subsubsection{Acquisition of Core Samples}

The TAT recommends drilling of new boreholes for acquisition of core for depth-discrete sample collection at locations near wells showing premature breakthrough. According to monitoring data reported in January 2004, there are six locations along the existing barrier where breakthrough has occurred. Hence, the TAT recommends a minimum of six borcholes be drilled for the aquifer characterization study. Sample collection procedures previously used for ISRM wells should be followed to maximize sample integrity and maintain field conditions. Continuous cores should be collected from approximately one foot above the water table to the base of the aquifer. Sampling intervals should include a significant number $(-8-15)$ of depth-discrete samples in each borehole so that a detailed investigation of aquifer heterogeneity can be conducted. Data from these samples can then be correlated with data collected using other methods, such as the EBF and geophysical logs.

\subsubsection{Physical Characterization}

The cores should be divided into 6-inch discrete samples to be photographed immediately following acquisition to illustrate the degree of sediment reduction. Physical analyses should include dry bulk density, porosity, grain-size distribution, and mass fraction. 
WMP-28119

Revision 0

\subsubsection{Chemical Characterization}

The objective of the chemical analyses is to improve the understanding of depth-discrete variability in the quantity and distribution of solid iron phases, including both $\mathrm{Fe}(\mathrm{II})$ and $\mathrm{Fe}(\mathrm{III})$, chromium, and sulfur. Correlations within these data will improve understanding of chemical mechanisms operating to immobilize the chromium in both reduced and oxidized states. The distribution of iron may provide information on preferential flow paths. The mass of chromium deposited may provide information on efficacy of the ISRM process. Sulfur data may provide information about its association with chromium and the form of the iron. The TAT recommends that each sample be analyzed for total chromium, iron, and sulfur. Samples from each interval shall be digested using nitric acid with microwave heating to dissolve only secondary minerals. A subset of samples should be further analyzed as follows:

- sample oxidation to estimate the mass of field-reduced sediment and field-reduced $\mathrm{Fe}(\mathrm{II})$, as siderite and as adsorbed $\mathrm{Fe}(\mathrm{II})$;

- citrate-dithionite-bicarbonate extraction (Locppert and Inskeep, 1996) to quantify crystalline $\mathrm{Fe}$ (III) (goethite and/or hematite) and amorphous ferric oxyhydroxide;

- acid ammonium oxalate (Loeppert and Inskeep, 1996) to quantify the amorphous $\mathrm{Fe}$ (III) (Ferrozine Method);

- sample reduction followed by oxidation to determine the maximum amount of laboratory-reduced Fe(II);

- scanning electron microscope or $\mathrm{X}$-ray absorption near-edge structure for identification of possible chromium phases [e.g., $\mathrm{Cr}(\mathrm{OH})_{3}(\mathrm{~s})$ and $\mathrm{Cr}_{\mathbf{x}} \mathrm{Fe}_{1}$. $\left.{ }_{x}(\mathrm{OH})_{3}(\mathrm{~s})\right]$ in samples with abundant field-reduced $\mathrm{Fe}(\mathrm{II})$;

- total chromium (SW-846 Method 3050) in samples with abundant ficld-reduced $\mathrm{Fe}(\mathrm{II}) ; \mathrm{Cr}(\mathrm{VI})$ (SW-846 Method 3060A); filtered extract analyzed for total chromium (EPA Method 200.8) and $\mathrm{Cr}$ (VI) using SW-946 Method 7196A; to quantify the amount of solid phase $\mathrm{Cr}(\mathrm{VI})$ and $\mathrm{Cr}(\mathrm{III})$.

Correlation of indicators of chemical heterogeneity with physical heterogencity measurements will help identify the specific preferential pathways within the ISRM barrier where breakthrough is occurring or may occur soon.

\subsection{Additional Characterization Methods}

The following sections describe additional methods for depth-discrete characterization that should be considered within the overall budget and schedule. They were evaluated to be medium-to-low rather than high priority due to factors such as relative cost, technology maturity, and ability to provide depth-discrete information. These technologies should be utilized on a limited basis, if additional funding is available for characterization of aquifer heterogeneity. 


\subsubsection{Tracer Tests}

Single-well tracer tests can provide information on groundwater-flow characteristics (e.g., flow velocity) and aquifer properties (i.e., vertical distribution of $\mathrm{K}$, effective porosity). Single-well tracer tests include tracer-dilution and tracer-pump-back tests. These tests can provide an additional opportunity for identification of preferential pathways within the barrier and to enhance design of barrier mending operations. Conduct of such tests on a limited basis to compare the data to other data such as EBF and geophysical logging will ensurc a more robust understanding of aquifer heterogeneity.

A single-well bromide tracer test was performed at the 100-D Area during the ISRM treatability testing (Williams et al., 2000). The main objectives of the tracer test were to: 1) determine volumes and rates for the dithionite injection and 2) calculate breakthrough curves for wells at different radial distances from the injection well as an indirect measure of vertical and horizontal heterogeneities. Results of this test indicated that tracer arrival times were significantly faster for the upper ( $83-89 \mathrm{fect})$ portions of the aquifer as compared to the lower portions ( $93-99 \mathrm{feet}$ ).

For the tracer-dilution test, a bromide solution of known concentration is mixed within the well-screen section. The decline of tracer concentration (i.e., "dilution") with time within the well screen is monitored directly using a vertical array of bromide-specific ion-elcctrode sensors located at known depth intervals. The sensors are calibrated in the laboratory with standards of known bromide concentration prior to and following performance of the tracer-dilution test. Based on the dilution characteristics observed, the vertical distribution (i.e., heterogeneity) of hydraulic properties and/or in-well flow velocity can be estimated for the formation section penetrated by the well screen. The presence of vertical flow within the well screen can also be identified from the sensor/depth-dilution-response pattern. Further description of design, performance, and analysis of tracer-dilution test characterization investigations is provided in Halevy et al. (1966), Hall et al. (1991), Freeze and Cherry (1979), and Hall (1993). Detailed procedures to conduct standard, single-well, conservative tracer tests are provided in Pickens and Grisak (1981) and Molz et al. (1985).

Essential design elements of a tracer-dilution test include establishing a known, constant tracer concentration within the test section by mixing or circulating the tracer solution in the wellbore/test interval and monitoring the decline of tracer concentration with time within the test interval. The decline in tracer concentration within the wellbore can be analyzed to ascertain the hydraulic gradient, I (if the formation's K is known) or the testinterval $K$ (if the hydraulic gradient is known) using the analytical expressions described by Spane et al. (2003).

Following completion of the tracer-dilution test, the tracer can be recovered from the formation by pumping, and the results analyzed to assess the effective porosity within the test interval. The tracer pump-back includes the following basic test procedure:

- emplace a conservative tracer (bromide) within the well/aquifer system; 
WMP-28119

Revision 0

- define a prescribed residence (drift) time for the tracer to be dispersed within the aquifer;

- withdraw the tracer from the well/aquifer system by pumping at a constant rate;

- monitor tracer concentrations at the test well (bromide sensor/flow cell) and collect discretc groundwater samples for quantitative laboratory analysis.

The time required to recover the center of tracer mass from the aquifer provides information concerning effective porosity and mean groundwater velocity. Analytical methods available for the analysis of single-well, tracer injection/withdrawal tests include (in addition to the previously cited references) Güven et al. (1985), Leap and Kaplan (1988), and Hall et al. (1991). The procedure to analyze the tracer-pumpback results is described in detail in Spane et al. (2003).

The TAT recommends that limited single-well tracer tests be considered in some of the existing wells where breakthrough has occurred and in some of the planned wells in the barrier extension to provide additional data regarding vertical and lateral heterogeneity in the aquifer and quantification of flow to be used for barrier mending or extension design.

\subsubsection{Ilydraulic Tests}

The TAT recognizes that hydraulic data have been collected at various phases of well construction and during lixiviant injection. The presence of a large number of wells screened in a single aquifer in the 100-D Area offers the opportunity for identification of preferential pathways based on the results of single and multiple-well hydraulic tests.

The TAT recommends analysis of existing hydraulic data should be performed with the goal of improving the understanding of aquifer heterogeneity, including identification of preferential pathways. Aquifer transmissivity and storativity should be estimated for each well. If necessary, new hydraulic testing should be conducted to fill data gaps. The results of this hydraulic test analysis should then be integrated with other aquifer characterization tests, such as the EBF data and borehole geophysics, to assist in identification of preferential pathways throughout the length of the barrier.

\subsubsection{Modeling}

Mathematical modeling has been performed to integrate results from the bench-scale experiments with site-characterization information. Reactive-transport numerical models were also used to interpret the results of these experiments to determine reaction kinetics at large scales. To-date, sufficient characterization data have not been collected to build realistic models of the barrier. Instead, predictions of barrier longevity have assumed a homogencous aquifer.

The TAT recommends that the primary emphasis be placed on collection of sufficient depth-discrete data to improve the understanding of aquifer heterogeneity. Once that understanding has been obtained, modeling can be used to develop a more sophisticated 
WMP-28119

Revision 0

estimation of barrier longevity and the system can be designed to more robustly address the preferential pathways that are controlling barricr performance.

\subsubsection{Cross-Borehole Geophysics}

Cross-borchole geophysics is typically utilized to detect changes in subsurface conditions that involve fluid migration. Various borchole geophysical tools, such as resistivity, seismic, electromagnetic, and radar have been applied in this geometry. The tools have often been applied to monitor a remediation technology that involved injection of fluids into the subsurface.

The geophysical source or transmitter is placed in one borehole and depth-discrete receivers are placed in a second borchole. The source is moved to various depths within the first borehole, thus allowing collection of data from a series of measurements that vary in depth. These data can be processed to produce a cross-section that depicts a geophysical parameter characteristic of the earth between the two boreholes. Data are typically collected before and during or after a fluid injection so that the difference in conditions can be depicted. For example, electrical resistance tomography (ERT) has been utilized to map numerous types of fluids (water, air) and also changes in temperature as a result of steam injection. It is possible that ERT could be utilized to map the injection of the dithionite solutions by collection of data before and immediately after injection.

Limitations of cross-borehole geophysics are the distance between boreholes (becomes very expensive if there is a need to cover a large area), the necessity to drill and install boreholes decper than the targeted interval of interest (so that the tomographic rays cross the volume of interest), and the cost.

The TAT recommends that cross-borehole geophysics be considered for mapping of fluid flow through preferential pathways during lixiviant injections, by comparing "before" and "after" tomograms. A small demonstration that utilizes ERT and possibly other geophysical tools could be applied across one or two locations along the barrier during mending, if funds are available. The biggest cost might be related to the requirement to install nvo new boreholes at each cross-section location. The tomographic boreholes would have to extend below the base of the aquifer in order to image the entire thickness of the aquifer and would have to be constructed of materials appropriate for the particular type of geophysical tool (some require steel and some plastic). The opportunity to image fluid flow in the subsurface could provide information that would contribute significantly to understanding of the heterogeneity of the subsurface.

\subsubsection{Flux Testing}

The TAT recommends that llanford consider limited testing of a new "passive flux meter" (PFM) to provide depth-discrete, time-integrated estimates of contaminant and fluid flux within and outside the barrier. The PFM could be utilized as an enhancement to the technologies previously recommended in Section 3.0. However, because of its relative immaturity, it should be considered as a limited test. It does have great potential 
WMP-28119

Revision 0

to provide information regarding the relationship between $\mathrm{Cr}$ and flow, which could help with assessment of the magnitude of the problem.

The PFM is a self-contained permeable unit that is inserted into a well such that it intercepts groundwater flow without retaining it. The interior of the meter is comprised of hydrophobic and hydrophilic permeable sorbents that retain dissolved organic and inorganic contaminants present in the fluid that flows through the unit. The sorbent matrix is also impregnated with known amounts of one or more fluid-soluble 'resident tracers.' These tracers are leached from the sorbent at rates proportional to the fluid flux. The PFM is exposed to groundwater flow for a period ranging from days to months. Next, the meter is removed and the sorbent carefully extracted to quantify the mass of all contaminants intercepted and the residual masses of all resident tracers. The contaminants masses are used to calculate time-averaged contaminant mass fluxes, while residual resident tracer masses are used to calculate cumulative fluid flux (Annable et al., 2003; Hatfield et al., 2002; Hatfield et al., 2003; Klammler et al., 2003).

If Hanford decides to pursue demonstration of this technology, the TAT recommends that PFMs be installed in both up-gradient and down-gradient wells in the 100-D Arca.

Down-gradient measurements can be used to estimate the cumulative $\mathrm{Cr}$ flux emanating from the barrier. Up-gradient measurements can be made to estimate the $\mathrm{Cr}$ mass loading into the reactive barrier. The difference in the response between the up-gradient and down-gradient PFMs could be attributed to the treated mass of $\mathrm{Cr}$. For more information about PFMs, contact Kirk Hatfield at University of Florida (email: khatf@ce.ufl.edu).

\subsubsection{FLUTe Conductivity Profiler}

The TAT recommends that Hanford consider a limited demonstration of the FLUTe liner system for measurement of depth-discrete hydraulic conductivity to compare to the EBF. The FLUTe liner, made of a urethane-coated Nylon fabric in tubular form is often installed in borcholes in the subsurface to collect depth-discrete water or vapor samples. The flexible liner is emplaced from a shipping reel by eversion into the borehole. As the liner is emplaced, it is filled with water so that it seals against the borehole wall as it descends into the borehole. FLUTe liners have been utilized at hundreds of sites, including DOE sites, for these types of applications. A recent advance is the application of the FLUTe liner to measure depth-discrete hydraulic conductivity. An effective transmissivity profile is obtained by measuring the installation rate and the level of excess head inside the liner. As the liner descends into the borehole below the water table, water flows out of the hole. The liner descent rate is controlled by the flow rate of the water out of the hole. This hydraulic conductivity profiling application has been compared to straddle packer results with extraordinary results.

\subsubsection{Surface Geophysics}

Surface geophysical techniques have limited application because of the thickness and character of the unsaturated zone (about 85 feet of mixed sand and gravel with lenses of silt and clay). Surface geophysics would not provide the depth-discrete detail required to solve this problem and thus is not recommended. 
WMP-28119

Revision 0

\subsection{Summary Recommendations to Improve Understanding of the Problem}

The TAT recommends that an aquifer characterization investigation be conducted in the vicinity of the current barricr to improve the understanding of lateral and vertical, physical and chemical heterogeneity within the aquifer, which will target understanding of the cause and magnitude of the problem. In addition, depth-discrete aquifer characterization should be conducted during installation of new wells to be installed. Multiple aquifer-characterization tools should be utilized to collect a robust, data set that can be integrated for an enhanced understanding of the lateral and vertical heterogeneity within the formation. Methods that provide depth-discrete characterization data are preferred so that a detailed understanding of aquifer variability can be obtained. Many of these methods are relatively inexpensive and yet provide significant information that can be used to design and operate an improved remediation system. Prior to initiation of the aquifer characterization investigation, existing data should be integrated and analyzed to produce a conceptual model that can then be refined based upon the results of the aquifer characterization. The conceptual model can be utilized to select drilling locations for new boreholes.

The TAT recommends the following approach to aquifer characterization:

1) conduct geophysical logging and perform EBF measurements in all existing wells;

2) utilize the data collected in \#1 and all prior data to construct a 3-D conceptual model detailing geology, hydrology, and chemistry (groundwater and aquifer materials) along the existing barrier;

3) utilize the conceptual model to target locations for drilling of new boreholes, focused primarily near existing wells showing breakthrough;

4) conduct depth-discrete characterization through drilling of new borcholes, conduct geophysical logging and EBF in new borcholes and perform limited tracer and hydraulic tests;

5) refine the conceptual model based upon the newly collected data; and

6) utilize the refined conceptual model to design bench-scale tests for mending of the existing barrier.

The following table shows a prioritized list of technologies recommended for the aquifer characterization investigation and recommendations for their implementation. 
WMP-28119

Revision 0

Table 1. Prioritization of Technologies Considered or Recommended for $\Lambda$ quifer Characterization

\begin{tabular}{|l|c|c|l|}
\hline \multicolumn{1}{|c|}{ Technology } & Priority & $\begin{array}{c}\text { Relative } \\
\text { Cost }\end{array}$ & \multicolumn{1}{|c|}{ Comments } \\
\hline Borehole Geophysics & High & Low & $\begin{array}{l}\text { Use in all existing wells and all } \\
\text { new boreholes }\end{array}$ \\
\hline $\begin{array}{l}\text { Electronic Borehole } \\
\text { Flowmeter }\end{array}$ & Hligh & Low & $\begin{array}{l}\text { Use in all existing wells and all } \\
\text { new borchole }\end{array}$ \\
\hline $\begin{array}{l}\text { Depth-Discrete Core } \\
\text { Analysis (physical and } \\
\text { chemical parameters) }\end{array}$ & High & High & $\begin{array}{l}\text { Necessary to ground truth other } \\
\text { technologies; critical to obtain } \\
\text { depth-discrete data that have not } \\
\text { been previously collected on a } \\
\text { detailed scale }\end{array}$ \\
\hline $\begin{array}{l}\text { Tracer/Hydraulic } \\
\text { Tests }\end{array}$ & Medium & Low & $\begin{array}{l}\text { May provide useful data at low } \\
\text { cost; consider limited testing at one } \\
\text { or two breakthrough locations; } \\
\text { definitely include previous work in } \\
\text { data analysis phase of investigation }\end{array}$ \\
\hline Flux Testing & Low-Medium & Low- & $\begin{array}{l}\text { Relatively untested but great } \\
\text { potential to providing valuable } \\
\text { information related to magnitude } \\
\text { of the problem; consider limited } \\
\text { testing }\end{array}$ \\
\hline $\begin{array}{l}\text { Cross-Borchole } \\
\text { Geophysics }\end{array}$ & Low & Very High & $\begin{array}{l}\text { Provides continuous spatial } \\
\text { information, but extremely } \\
\text { expensive; may be uscful to map } \\
\text { preferential pathways during } \\
\text { lixiviant injection; consider limited } \\
\text { testing }\end{array}$ \\
\hline $\begin{array}{l}\text { FLUTe Hydraulic } \\
\text { Conductivity Profiling }\end{array}$ & Low & $\begin{array}{l}\text { Low- } \\
\text { Medium }\end{array}$ & $\begin{array}{l}\text { Consider limited testing; has } \\
\text { potential for low-cost method; may } \\
\text { be useful to compare with EBF }\end{array}$ \\
\hline Modeling & Low & $\begin{array}{l}\text { Will be required to predict barrier } \\
\text { longevity after investigation is } \\
\text { completed but not required now }\end{array}$ \\
\hline
\end{tabular}


WMP-28119

Revision 0

This page intentionally left blank 
WMP-28119

Revision 0

\subsection{RECOMMENDATIONS FOR MENDING THE BARRIER}

The TAT developed a number of recommendations for mending the barrier, based upon the hypothesis that the primary causes of premature breakdown are: 1) physical and chemical aquifer heterogencity, and 2) presence of other oxidants in the groundwater. Development of a strategy for barrier repair is dependent on identification and characterization of the preferential pathways and determination of the amount of reactive iron remaining the subsurface with depth, as described in Section 3.0 (i.e.. the recommended detailed aquifer characterization study). Mending the barrier may involve development of a modified operational approach by applying alternative lixiviants or mending agents where preferential pathways or intervals of limited reactive iron have been identified or may involve a totally new approach to aquifer treatment.

Mending recommendations must be finalized after completion of the detailed aquifer characterization study. A number of alternatives for mending must be evaluated. These alternatives may involve injection of one of the following lixiviants, either alone, or more likely in combination with another lixiviant. Lixiviant options include:

1) dithionite;

2) iron, as a solid (micro or nano) or liquid;

3) calcium polysulfide; and

4) biostimulants.

The TAT recommends that a preliminary cost evaluation of these altermatives be conducted to identify the most cost-effective approaches to be considered for bench-scale testing, after conduct of the aquifer characterization investigation. Bench-scale testing is required to determine proof-of-principle, performance, preliminary design, and costs. The bench-scale studies should involve: (a) laboratory jar tests to evaluate the optimum reagent solution concentration and the volume that would be required to stabilize the $\mathrm{Cr}$. and (b) dynamic column studies to assess the long-term effectiveness of the chemical fixating agent and to simulate a I-D treatment operation in the saturated zone. Issues, such as pore plugging and alteration of hydro-geochemical properties following injection, should also be evaluated as part of the column studies.

Each of the mending options is described in the sections below.

\subsection{Dithionite}

Dithionite has been applied effectively to the aquifer to reduce $\mathrm{Cr}(\mathrm{VI})$ in the groundwater. The dithionite injections have created a continuous barrier, enabling an effective radius of influence. However, the longevity of the treatment is now in question. Results of the aquifer characterization investigation will be critical to our understanding of the viability of the dithionite to meet long-term performance requirements. Because the dithionite treatment relies upon the presence of sufficient reactive iron in the subsurface, the determination of whether there is sufficient reactive iron, on a foot-byfoot basis, remaining in the subsurface is critical to the evaluation of the practicality of 
dithionite re-injection. If there is found to be sufficient iron in the formation, the strategy of reinjection of dithionite may be valid. However, the TAT anticipates that this will not be the case within the preferential pathways.

\subsection{Calcium Polysulfide}

In recent years, sulfur-based metal fixation technologies have been the focus of an increasing number of research studies and commercial applications for treating heavy metal contamination in soil and groundwater. One such sulfur-based reagent, particularly suitable for treating heavy metals like $\mathrm{Cr}(\mathrm{VI})$ is calcium polysulfide $\left(\mathrm{CaS}_{\mathrm{x}}\right)$. Calcium polysulfide, which is water soluble, has been demonstrated as a successful metal-fixating agent for many heavy metals (e.g., arsenic, lead, copper, cadmium). Numerous applications of calcium polysulfide specifically for $\mathrm{Cr}(\mathrm{VI})$ have been successfully conducted at industrial sites over the last ten years (personal communication Rouse to Kaback, 2004; Rouse et al., 1996).

Calcium polysulfide precipitates highly soluble metals as less soluble and non-toxic sulfides. Calcium polysulfide reduces $\mathrm{Cr}(\mathrm{VI})$ to $\mathrm{Cr}(\mathrm{III})$, which is then precipitated readily as chromium hydroxide and/or as iron chromium hydroxide $\left[\mathrm{Cr}_{\mathbf{x}} \mathrm{Fe}_{1 \cdot \mathrm{x}}(\mathrm{OH})_{3}\right]$ with resultant solubility many orders of magnitude lower than that of pure chromium hydroxide. The reaction mechanisms describing the $\mathrm{Cr}(\mathrm{VI})$ oxidation/reduction processes with calcium polysulfide are not documented in the literature. All the possible reactions are numerous and too hypothetical to describe in this report. A generalized equation describing the overall process is given as follows.

$$
2 \mathrm{CrO}_{4}{ }^{2-}+3 \mathrm{CaS}_{5}+10 \mathrm{H}^{+}=2 \mathrm{Cr}(\mathrm{OH})_{3}+15 \mathrm{~S}+3 \mathrm{Ca}^{2+}+2 \mathrm{H}_{2} \mathrm{O}
$$

Chromium hydroxide is much less soluble in the neutral pH region between 7 and 9 , with solubility increasing both under acidic and alkaline conditions. Reducing conditions created following the addition of calcium polysulfide enable reduction of other oxidized species such as $\mathrm{Fe}(\mathrm{III})$ to $\mathrm{Fe}$ (II), according to the reaction below, enhancing the reduction of $\mathrm{Cr}(\mathrm{VI})$.

$$
3 \mathrm{Fe}(\mathrm{II})+\mathrm{CrO}_{4}^{2 \cdot}+3 \mathrm{e}^{-}+5 \mathrm{H}^{+}=\mathrm{Cr}(\mathrm{OH})_{3}+3 \mathrm{Fe}(\mathrm{III})+\mathrm{H}_{2} \mathrm{O}
$$

Any chromium hydroxide formed is also known to form surface complexes on sediment particles thereby sequestering the release of the dissolved forms (Sass and Rai, 1987). As the reaction between $\mathrm{CaS}_{\mathrm{x}}$ and $\mathrm{Cr}(\mathrm{VI})$ take place in groundwater, intermediate reaction products further react to form benign end products like, calcium sulfate $\left(\mathrm{CaSO}_{4}\right)$, calcium carbonate $\left(\mathrm{CaCO}_{3}\right)$ and elemental sulfur $\left(\mathrm{S}_{8}\right)$.

Calcium polysulfide, marketed under the trade name of Cascade ${ }^{\otimes}$, is sold as a $29 \%$ aqueous solution of $\mathrm{CaS}_{x}$ (where, $\mathrm{x}=2-5$ ). Commercial quantities in 55-gallon drums are available from "Best Sulfur Products," located in Fresno, CA (Phone: 1.800.800.4854). Also referred to as "lime sulfur solution," it is a deep orange-red, alkaline solution with a pH between 11.3 and 11.5 and a specific gravity of 1.273 . This is 
WMP-28119

Revision 0

an inexpensive reagent ( $\sim 3.5 /$ gallon), which can be easily pumped into injection wells. Upon introduction, the polysulfide solution reacts directly with the $\mathrm{Cr}(\mathrm{VI})$.

Prior to field injection, bench-scale treatability tests, as described at the beginning of the section, should be performed to evaluate the right dosage (concentration and volume) of calcium polysulfide that would be required for effective fixation of $\mathrm{Cr}$ in the groundwater in the 100-D Area. One of the advantages of calcium polysulfide as compared to dithionite is that it is a direct reduction reaction and does not require the presence of reactive iron in the aquifer.

\subsection{Solid and/or Liquid Iron Additives}

The direct addition of iron as a reductant also has the advantage over dithionite in that it does not require the presence of iron in the aquifer materials. Injection of both solid (as zero-valent iron) and liquid forms (as ferrous iron) have been investigated for aquifer treatment. Solid zero-valent iron has been developed in micron and nanoscale forms for injection as a powder. It is well known that in the presence of zero-valent iron, $\mathrm{Cr}(\mathrm{VI})$ undergoes direct, instantaneous reduction to thermodynamically stable $\mathrm{Cr}(\mathrm{lll})$, which then precipitates as chromium hydroxide or forms solid solution with iron. The entire reaction is outlined by the following equation:

$$
3 \mathrm{Fe}^{0}+\mathrm{CrO}_{4}{ }^{2-}+8 \mathrm{H}_{2} \mathrm{O}+2 \mathrm{H}^{+}=\mathrm{Fe}_{3} \mathrm{Cr}(\mathrm{OH})_{12}(\mathrm{~s})+3 \mathrm{H}_{2}
$$

Zero-valent iron has been applied most frequently in permeable reactive barriers created by trenching. The high cost of trenching as well as significant depth limitations for trench construction has driven the search for other methods for emplacement of zerovalent iron.

To minimize costs of mending, iron additions could be designed for emplacement only in the high-permeability intervals or only in those areas where preferential pathways have been identified by the detailed aquifer characterization study. Targeting of preferential pathways for injection in each well will require more detailed aquifer characterization, which will add additional costs. Broad application of a low-cost iron alternative, liquid ferrous iron, may provide the most cost-effective approach, where iron-bearing solutions will primarily follow the preferential pathways that require the treatment.

\subsubsection{Micron-Sized Zero-Valent Iron Emplaced with Shear-Thinning Polymers}

An innovative approach for emplacement of zero-valent iron into high-permeability zones is the injection of suspensions of colloidal-sized ( $1 \mu \mathrm{m}-3 \mu \mathrm{m}$ diameter) iron particles. Because only a few weight percent iron is emplaced into the aquifer, there is no effect on hydraulic conductivity.

This approach, demonstrated at the bench-scale using Hanford sediments, applies steric stabilizers and rheological modifiers to greatly reduce particle-particle interaction and particle settling. Because these suspensions are of a higher viscosity than water, they will 
have a tendency to flow preferentially to the more permeable zones where treatment is needed.

Bench-scale laboratory experiments, conducted by PNNL, were focused on suspension development through the usc of a polymer additive to decrease the settling rate of micrometer-sized particles of zero-valent iron $\left(\mathrm{Fe}^{0}\right)$. Later work focusing on the injection of these suspensions into porous media demonstrated results that were quite promising, with no adsorption of the polymer material on the aquifer materials and fairly even distribution of iron throughout the column (Appendix E). This work was conducted using both quartz sand and natural Hanford aquifer materials (Kaplan et al. 1994; Kaplan et al. 1996; Cantrell and Kaplan 1997a, 1997b, and unpublished results discussed below).

The single largest expense of this technology is the cost of the micron-sized iron. This material is commercially available at approximately $\$ 7.00 / \mathrm{lb}$. It is possible to estimate the cost to "fix" one of the wells where chromate has broken through the ISRM barrier. If it is assumed that a suspension containing $1 \%$ iron is injected into a well for a radius of $30 \mathrm{feet}$, an aquifer thickness of $10 \mathrm{feet}$, and a porosity of $30 \%$, it is estimated that 5,300 Ibs of iron would be needed. This would cost about $\$ 37 \mathrm{~K}$ for the iron. Because only a few of the wells along the entire barrier need to be "fixed," this approach could be cost effective.

The predicted longevity for the lixiviant addition to the preferential pathways can be estimated based on the following assumptions.

- a preferential flowpath, which is 10 meters long with a diameter of $3 \mathrm{~cm}$ and a porosity of 30\% exists;

- groundwater flows through this flowpath at one foot per day;

- the primary oxidants are dissolved $\mathrm{O}_{2}$ at $8 \mathrm{mg} / \mathrm{L}$ and $\mathrm{NO}_{3}{ }^{\circ}$ at $40 \mathrm{mg} / \mathrm{L}$; and,

- the treatment fills the pores by injecting this channel with a suspension of $1 \% \mathrm{Fe}^{0}$ and the iron settles out within the channel.

Using these assumptions, a preliminary estimate of the longevity of the treatment is approximately 20 years.

\subsubsection{Nanoscale Zero-Valent Iron}

Metallic nanoscale zero-valent iron has been tested as an in situ reductant since the late 1990's. Nanoscale iron is about 10 to 1,000 times more reactive than conventional iron powders and because of the smaller $(\sim \mathrm{nm})$ particle size has much greater surface area available for reaction. Nanoscale iron can be suspended in slurry and pumped directly into the target contaminant zones through the injection wells or using a direct-push rig, such as the Enhanced Access Penetration System (EAPS) recently demonstrated at Hanford.

The ideal size range of the nanoscale particles for subsurface application is between 100 and $500 \mathrm{~nm}$, which is large enough to obviate attractive forces between the mineral matrix and the iron, while also small enough to minimize gravitational settling (Elliot and 
WMP-28119

Revision 0

Zhang, 2001). Actual particle sizes may range from $10 \mathrm{~nm}$ to 0.1 micron. Because the bulk of the particles are typically within the upper end of the size range, there is little concern regarding mobilization at normal groundwater velocities.

There are currently two methods that produce nanoscale colloids with optimal reactivity and longevity. They are: (i) aqueous synthesis of nanoscale $\mathrm{Fe}$ with borohydride (Wang and Zhang, 1997) and (ii) production of nanoscale colloids using a modification of conventional ball-milling techniques (Pekala et al., 1997; Revesz et al., 2000). Although the borohydride precipitation method is designed to impart longer reactive life than conventional iron filings or ferragel supported nanoscale colloids (Ponder et al., 2001), the primary disadvantage of this form of iron is its high cost of production per pound of the material. Recently, Lehigh University has developed a new chemical route to manufacture these particles that may lower the cost per pound of this material from $\$ 250 / \mathrm{lb}$ to $\$ 20 / \mathrm{lb}$ (http://www.nsf.gov/od//pa/news/03/pr0394.htm). Although the cost is higher than conventional iron filings, the ability to emplace this material in deeper subsurface targets will drive the economics in favor of the nanoscale colloids.

Because of the extremely small particle size, it is expected that nanoscale iron can be delivered via direct injection into the ISRM injection wells and be able to travel a significant distance into the formation. Previous testing at a field site indicated a radius of influence of about 6-10 $\mathrm{m}$ from the injection well (Glazier et al., 2003). Greater radius of influence could be achieved by injecting the reagents under pressure or by setting up an extraction well down-gradient to draw the slurry through the treatment zone. Benchscale testing is recommended so that the exact amount of material required for a single injection event and the radius of influence can be calculated. Other advantages of nanoscale iron include: no $\mathrm{pH}$ buffer is required and nanoscale colloids can be mixed directly with raw water in an above-ground holding tank prior to injection (Glazier et al., 2003).

The primary concern related to longevity limitations is the elimination of active treatment sites on the media particles due to oxidation and/or the presence of other fouling. Because nanoscale colloids have specific surface area between 10 and 1000 times greater than conventional iron media and electron transfer processes associated with $\mathrm{Cr}$ reduction rely on the availability of reaction sites on the iron media surface, the significantly greater surface area of the nanoscale colloids is predicted to possess greater activity. The use of boron as a solute in the aqueous precipitation process to form nanoscale colloids provides superior control over the rate at which iron dissociates water to form hydrogen (corrosion reaction) compared to pure metallic iron, thereby increasing its longevity in the subsurface for 6 to 8 weeks (Zhang, 2003). Nonetheless, site-specific colloid longevity issues should be tested beforehand by conducting bench-scale long-term column studies as part of the treatability testing.

\subsubsection{Iron In Solution}

In contrast to injection of particulate zero-valent iron as discussed in the previous two sections, supplemental ferrous iron (Fe[II]) could be added to iron-depleted zones or 
throughout the aquifer. A liquid mending agent has an advantage over a particulate agent in terms of its ability to disperse within the aquifer to greater distances from the injection well. In addition, liquid Fe(II) is likely a more cost-effective means of directly emplacing iron in the aquifer. Introduction as Fe(II) eliminates the need for subsequent dithionite injection.

However, there is less bench-scale experience with the use of dissolved Fe(II) to emplace iron in the subsurface. In principle, Fe(II) should precipitate as ferrous hydroxide.

$$
\begin{aligned}
\mathrm{FeCl}_{2}[\text { dissolved }]+\mathrm{CaCO}_{3}[\text { calcite }]+2 \mathrm{H}_{2} \mathrm{O} \\
\quad=\mathrm{Fe}(\mathrm{OH})_{2}[\text { ferrous hydroxide }]+\mathrm{Ca}^{2+}+2 \mathrm{Cl}^{-}+\mathrm{HCO}_{3}^{-}+\mathrm{H}^{+}
\end{aligned}
$$

However, the TAT recommends that bench-scale tests be conducted to confirm the feasibility of this method prior to its use at Hanford.

Recently, EPA demonstrated Fe(II) precipitation in an aquifer by injecting ferrous sulfate, dissolved in aqueous solution with sodium dithionite added as a redox buffer to help keep iron reduced to $\mathrm{Fe}$ (II) (R. Ludwig, web site material). The demonstration was successful at introducing $\mathrm{Fe}$ (II) into the formation and $\mathrm{Cr}$ (the target contaminant) concentrations decreased. The $\mathrm{pH}$ of the formation at this site was high (about 11), which probably contributed to the formation of ferrous hydroxide. However, even at this high $\mathrm{pH}$, some iron mobility was observed down-gradient of the injection (personal communication R. Ludwig to S. Morrison, 2004). In bench-scale tests at the DOE Grand Junction Office, ferrous hydroxide readily formed by injecting ferrous chloride into a sediment containing lime $\left[\mathrm{Ca}(\mathrm{OH})_{2}\right]$ (unpublished data, DOE Grand Junction Office). As the ferrous chloride contacted the high $\mathrm{pH}$ conditions imposed by the lime, dark green concentric bands of ferrous hydroxide were emplaced. At Hanford, perhaps lime could be injected before the ferrous chloride solution, if Hanford sediments don't contain sufficient pll buffering capacity to allow precipitation of fertous hydroxide.

\subsection{Biostimulation}

The TAT recommends consideration of biostimulation as an altemative to dithionite or as an enhancement to any of the altematives considered. $\mathrm{Cr}(\mathrm{VI})$ can be reduced to $\mathrm{Cr}$ (III) by chemical and/or biological means. The direct enzymatic reduction of $\mathrm{Cr}(\mathrm{VI})$ by numerous bacteria has been reported (Lovley, 1993; Lovley, 1997). Microbial reduction of $\mathrm{Cr}(\mathrm{VI})$ has been observed under both aerobic and anaerobic conditions, but the physiological role of the acrobic reduction has not been well defined. The potential use of biostimulation for reduction and sequestration of $\mathrm{Cr}$ has drawn interest and been the subject of numerous investigations and reviews (Lovley, 1993; Losi, 1994; Lovley, 1997). Some applications of biostimulation in concert with calcium polysulfide to remove $\mathrm{Cr}(\mathrm{VI})$ from groundwater at industrial sites have been been conducted over the last ten years (personal communication Rouse to Kaback, 2004).

Two general approaches for utilizing biostimulation at the 100-D Area were initially considered by the TAT. One approach involves injection of an organic nutrient, such as 
Hydrogen Release Compound (HRC ${ }^{\circledR}$ ) or lactate, into the existing wells to enhance microbial activity and promote in situ metal reduction through either direct enzymatic reduction of $\mathrm{Cr}(\mathrm{VI})$ or indirect reduction via the production of $\mathrm{Fe}$ (II) and/or sulfide. The other proposed approach involves addition of an inexpensive complex organic source upgradient of the barrier to stimulate heterotrophic bacterial activity for the purpose of removing $\mathrm{O}_{2}$ and $\mathrm{NO}_{3}{ }^{-}$from the groundwater before it reaches the barrier.

Organic amendments, such as lactate and $\mathrm{HRC}^{\circledR}$ (a patented polylactate compound produced by Regenesis), are relatively expensive when compared with other organic substances, like molasses or alcohol. Thesc low-molecular weight organic acids are typically used to enhance specific populations of bacteria, such as metal- and/or sulfatereducing bacteria, which have been shown to reduce $\mathrm{Cr}(\mathrm{VI})$ under anoxic conditions (Lovley, 1997).

The rapid and cfficient chemical reduction of $\mathrm{Cr}(\mathrm{VI})$ by $\mathrm{Fe}(\mathrm{II})$ has also been demonstrated by numcrous investigators (Fruchter et al., 2000; Pettine et al., 1998), including at the ISRM barrier 100-D Area at the Hanford Site. Review of available litcraturc on the rates of abiotic and biotic $\mathrm{Cr}(\mathrm{VI})$ reduction suggests that chemical reduction of $\mathrm{Cr}(\mathrm{VI})$ by sulfide (at $\mathrm{pH}<5$ ) or $\mathrm{Fe}(\mathrm{II})($ at $\mathrm{pH}>5$ ) is significantly faster than direct enzymatic reductive pathways (Fendorf et al., 2000).

A potentially significant advantage of ISRM using dithionite is that in theory one injection produces sufficient redox buffering within the aquifer to last for several years (previously estimated at 24 years). However, this was not observed in practice at Hanford. In contrast, the organic amendments mentioned above would need to be provided relatively continuously (lactate) or periodically over time frames of one to several ycars $\left(\mathrm{HRC}^{\circledR}\right)$ to be effective.

The overall longevity and effectiveness of the barrier is dependent on the concentrations of all potential $\mathrm{Fe}$ (II) oxidants moving through the treatment zone, including $\mathrm{O}_{2}$ and $\mathrm{NO}_{3}{ }^{-}$. Calculations based on average up-gradient concentrations of $\mathrm{Cr}(\mathrm{VI}), \mathrm{DO}$, and $\mathrm{NO}_{3}{ }^{-}$indicate that only a small fraction of the $\mathrm{Fe}$ (II) in the treatment zone is available for $\mathrm{Cr}$ reduction and the majority (93 to 99\%) is oxidized by DO and/or $\mathrm{NO}_{3}{ }^{-}$(Section 2.3). Thus, removing all or a portion of the $\mathrm{O}_{2}$ and $\mathrm{NO}_{3}{ }^{-}$by addition of a suitable organic substrate that enhances heterotrophic microbial respiration could extend the reactivity of the barrier significantly by removing most or all of the oxidants from the groundwater prior to reaction with the treatment zone.

Heterotrophic bacteria that couple the oxidation of complex sugars and other highmolecular weight organic compounds with the reduction of $\mathrm{O}_{2}$ and $\mathrm{NO}_{3}{ }^{-}$are ubiquitous in nature. Thus, combining a biological approach for removal of $\mathrm{O}_{2}$ and $\mathrm{NO}_{3}^{-}$up-gradient of the treatment zone with the chemical reduction of $\mathrm{Cr}$ in the barrier could prolong barrier longevity. Preliminary calculations based on the assumption of up-gradient groundwater being $\mathrm{O}_{2}$ saturated $\left(\mathrm{DO}=8.4 \mathrm{mg} / \mathrm{L}\right.$ ) and containing $58.8 \mathrm{mg} / \mathrm{L} \mathrm{NO}_{3}{ }^{-}$ (average for welis up-gradient of the barrier) indicate that approximately $420 \mathrm{mg} / \mathrm{L}$ sugar 
(e.g. glucose or equivalent) would be required to remove all the $\mathrm{O}_{2}$ and $\mathrm{NO}_{3}{ }^{-}$from the groundwater.

Rapid groundwater mounding during filling of the 182-D Reservoir indicates that water released near the surface can quickly move through the vadose zone to the water table. Near-surface rclease of water amended with inexpensive organic nutrients may be useful for biologically reducing $\mathrm{O}_{2}$ and $\mathrm{NO}_{3}{ }^{-}$in the groundwater up-gradient of the barrier. Delivery of the inexpensive organics could be done through the floor of the 182-D Reservoir or through a shallow trench. Industrial waste products that are high in biological oxygen demand (BOD) rather than commercially available sugar-based products, such as molasses, could contributc to the cost-effectiveness of this remedial approach and should be considered as a means of enhancing the longevity of the current ISRM barricr. A small-scale field demonstration to quantify transport of organics through the vadose zone would be appropriate.

Alternatively, if further investigation into the cause of barrier breakdown (as described earlier) indicates that dithionite may need to be reinjected much more frequently that previously thought, a conversion to a bioremediation approach using the existing wells in place of the dithionite may warrant consideration. While the organic carbon would need to be applied relatively continuously, low-cost organic substrates could be used to minimize annual material costs. Calculations assuming an up-gradient groundwater depth of $15 \mathrm{ft}$, a barrier length of $2600 \mathrm{ft}$, a groundwater linear velocity of $1 \mathrm{ft} / \mathrm{d}$, and organic addition to provide approximately $560 \mathrm{mg} / \mathrm{L}$ total organic carbon indicate that material costs would be less than $\$ 200,000$ annually. A potential limitation of this approach is a possible requirement for closer injection-well spacing. Groundwater modeling would be required to determine the necessity for addition of injection wells along the existing barrier length. In addition, previous investigations have shown that $\mathrm{Cr}$ (III) can be held in solution in the presence of organic compounds presumable as $\mathrm{Cr}$ (III)-organic complexes (Komori, et al., 1990; Wielinga et al., 2001) and therefore bench-scale tests using actual groundwater would need to be conducted to verify that $\mathrm{Cr}$ (III) could be precipitated and sequestered by the aquifer materials under field conditions.

In summary, bioremediation has the potential to extend the longevity of the barrier, if used in conjunction with the current technology by removing a significant portion of the oxidants $\left(\mathrm{O}_{2}\right.$ and $\left.\mathrm{NO}_{3}{ }^{-}\right)$from the groundwater up-gradient of the treatment zone within the barrier. Alternatively, if further investigation indicates that the physical and chemical heterogencities of the aquifer will likely continue to cause premature breakdown, bioremediation as a sole, replacement treatment technology might be considered. Because $\mathrm{O}_{2}$ and $\mathrm{NO}_{3}{ }^{-}$consume most ( $>95 \%$ ) of the reducing equivalents added to the aquifer, an inexpensive complex organic substrate, such as molasses or other high total organic carbon industrial byproduct could be used to enhance heterotrophic microbial activity. The most appropriate approach/technology for substrate delivery needs to be evaluated and tested in the ficld prior to full-scale application should this treatment approach prove to be feasible. 
WMP-28119

Revision 0

\subsection{The Pond Leakage Issue}

The TAT has significant concerns with the performance of the existing barrier and the barrier extension due to up-gradient leakage from the 182-D Reservoir. The 182-D Reservoir creates a groundwater mound that influences the direction of groundwater flow and has potential to flush large volumes of $\mathrm{O}_{2}$-rich water into the barrier, thus significantly impacting the operational efficiency for the planned barrier extension and likely impacting the existing barrier.

Groundwater flow patterns are very complex in the area of the present barrier and the planned extension. Temporal changes in river stage cause major changes in flow direction, but cannot be controlled or eliminated. Changes in the leakage rates from the 182-D Reservoir cause significant changes in flow direction. For example, the Fall 2003 water-table map shows a groundwater mound under the reservoir that resulted in groundwater flow from the area of the reservoir to and through the existing barrier as well as to the north-northeast and through the area of the planned barrier extension. Contaminated groundwater has been diverted around the northeast end of the existing barrier. Elimination of leakage from the reservoir would make operation of the present barrier and the planned extension much more effective.

The TAT recommends that: 1) use of the resenvoir be discontinued or 2) the reservoir be properly sealed to eliminate leakage or 3 ) the addition of an organic substrate to promote reduction of $\mathrm{O}_{2}$ and $\mathrm{NO}_{3}$ up-gradient of the barrier be implemented.

\subsection{A Supplemental Biological Treatment for the Dithionite Re-injection Option}

The current treatment zone of the ISRM barrier was established using a four-step approach, which consisted of an:

- an injection step in which sodium dithionite is injected;

- a post-injection push step were a low sodium dithionitc solution $(0.001 \mathrm{M})$ is injected to "push" the more concentrated dithionite solution further into the surrounding aquifer;

- a reaction step during which the dithionite is allowed to react with and reduce the ferric ion contained in aquifer sediments; and

- an extraction step to remove the residual sodium dithionite solution and reaction byproducts, such as, sulfate from the aquifer.

Plans for the barrier extension eliminate the last step, that of extraction. Re-injection operations could also consider this operational regimen. If so, higher concentrations of sulfate will be left in the near treatment-zone groundwater. Higher concentrations of sulfate in the groundwater may provide an opportunity to increase the reductive capacity of the barrier and the zone of influence by extending the life of the reductive reactions through stimulation of sulfate-reducing bacteria (SRB). 
SRB's gain energy for growth by coupling the oxidation of low molecular-weight organic compounds to the reduction of sulfate as shown in the following equation.

$$
2 \mathrm{CH}_{2} \mathrm{O}+\mathrm{SO}_{4}{ }^{2-} \rightarrow \mathrm{HS}^{-}{ }_{(3 q)}+2 \mathrm{HCO}_{3}^{-}+\mathrm{H}^{+}
$$

The sulfide produced from this biological reaction is a potent reductant, which can reduce residual iron and manganese oxyhydroxides in the aquifer materials, thereby producing additional Fe(II). Thus, the injection of a simple organic-carbon substrate along with or following the sodium-dithionite injection could provide two benefits:

- removal of reaction byproducts (i.e. sulfate) from the aquifer;

- extension of reaction time and expansion of the reducing zone.

The reaction would likely be limited within the treatment zone due to the elevated groundwater $\mathrm{pH}$.

Following the second injection of sodium dithionite in well D4-7 in August 2002, groundwater $\mathrm{pH}$ increased to about 11 and has decreased to 9.5 after almost 1.5 years (Figure 5). The pH at which SRB activity has been reported has ranged from $\mathrm{pH} 4$ to $\mathrm{pH}$ 9 (Barton, 1995). While the concentration of sulfate has increased significantly in downgradient wells like D4-1, groundwater $\mathrm{pH}$ has generally remained within a range that would support SRB activity (Figure 6). As the organic substrate is transported along with the sulfate to zones where the $\mathrm{pH}$ is favorable for $\mathrm{SRB}$ activity, sulfate could be degraded and additional reducing equivalents could be produced. Because almost all of the $\mathrm{O}_{2}$ and $\mathrm{NO}_{3}{ }^{-}$are removed during the initial dithionite reaction phase, all of the organic substrate could be utilized for reduction of residual metal oxides and sulfate, which would add to the efficiency and cost-effectiveness of this supplemental approach. 
WMP-28119

Revision 0
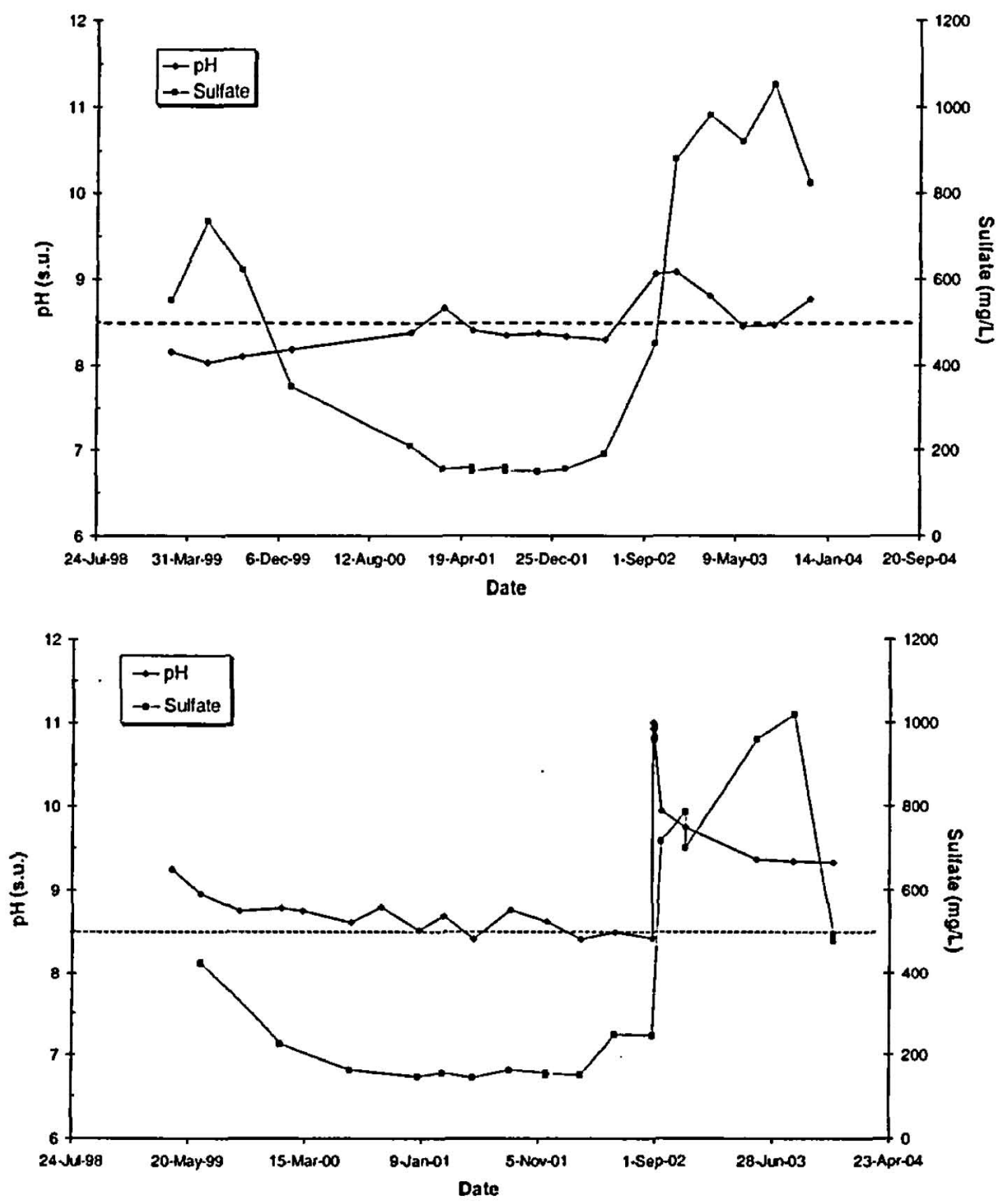

Figure 5. Measured pH and sulfate concentrations recorded at injection well 199. D4-7 versus time.

Figure 6. Measured plI and sulfate concentrations recorded at well 199-D4-1, which is down-gradient from the treatment well 199-D4-7. 
WMP-28119

Revision 0

\subsection{Recommended $\Lambda$ pproach for Mending the Barrier}

The TAT recommends the following approach for mending the barricr:

1) Perform preliminary screening of alternatives based upon results of aquifer characterization investigation and estimated costs to sclect those viable for benchscale testing. Consider testing of at least two alternatives in addition to testing of dithionite (possibly with altemative buffer, as described in Section 6.3), all with a focus on long-term performance. Consider biostimulation as an enhancement.Perform bench-scalc testing as appropriate.

3) Consider addition of biostimulation up-gradient.

4) Perform predictive modeling based upon results of bench-scale testing to estimate barrier longevity for each of the options.

5) Take the 182-D Reservoir out of service or install a liner to minimize leakage. 


\subsection{RECOMMENDATIONS FOR EXTENDING THE BARRIER}

The TAT recommends that during drilling of new injection and monitoring wells for the ISRM barrier extension, depth-discrete characterization data be collected from core samples to develop a good understanding of lateral and vertical, physical and chemical aguifer heterogeneities and hydrology of the barrier extension. The TAT recommends creation of a conceptual model to be used in design of the barrier extension. The depthdiscrete charactcrization should follow the recommendations in Section 3.0, which include core analyses in addition to geophysical logging and EBF measurements as a minimum. If funding is available, other technologies, as described in Section 3.0, should also be considered. Drilling of new injection and monitoring wells should consider recommendations provided in Section 6.0.

If the hydrology and aquifer characteristics of the barrier extension are similar to that of the existing barrier, the treatment system can likely be designed without further benchscale testing. If the system has significant differences, additional bench-scale testing will be required. 
Revision 0

This page intentionally left blank 
WMP-28119

Revision 0

\subsection{OTHER RECOMMENDATIONS}

\subsection{Alternative Drilling Approaches}

Barrier injection wells have been constructed using both reverse air rotary and cable tool drilling techniques. Concern about injection of air during drilling with the reverse air method has led to the decision to use the cable-tool method for new wells, including those proposed for the barricr extension. The TAT recommends that several drilling alternatives be considered to meet different access requirements.

The TAT believes that the reverse air rotary method can be used without significant introduction of air if the dual-wall drill steel is connected to a tri-cone or drag bit using a section of single-wall drill steel. This approach results in water and cuttings movement up through the holes in the bit (sucking action) without significant discharge of air into the aquifer. Casing would be advanced using a top-head driver. Application of this drilling technique for barrier wells may be limited by the amount of submergence required for operation. Removal of cobbles from the hole is also a potential problem.

The Enhanced Access Penetration System (EAPS), recently demonstrated in the 200 West Area of the Hanford Site, should be considered for installation of wells, as it may represent a cost savings. EAPS is a combination cone-penetrometer/air-rotary system. However, the smaller diameter tool likely injects small quantities of air into the aquifer if air rotary is required.

Sonic drilling should be considered for all investigative work where core is required. This would be particularly true for the mending investigation, where boreholes should be drilled to collect samples, but will not be completed as wells. Further investigation of the loss in permeability due to sonic drilling for well installation should be pursued.

\subsection{Well Development/Construction}

Creation of the barrier is dependent upon injection of the lixiviant into the screened interval in direct proportion to the hydraulic conductivity and thickness of individual subunits. For example, a screened interval may contain three layers of equal thickness with relative hydraulic conductivity values of 1,5 and 10 units. Injection should result in 1/16th of the lixiviant entering the first layer, 5/16ths of the lixiviant entering the second layer and $10 / 16$ ths of the lixiviant entering the third layer. This provides lixiviant in the same proportion as groundwater flow (given the same hydraulic gradient and effective porosity).

Formation damage caused by drilling and not repaired during well development can result in lixiviant injection that is not proportional to aquifer hydraulic properties. Barrier injection wells have been constructed using either cable tool or reverse air rotary methods by drilling and driving temporary casing (assumed to be 10-inch diameter) several feet into the Ringold Upper Mud (ISRM Barrier Well Completion Report for the 100-HR-3 
WMP-28119

Revision 0

Groundwater Operable Unit, Fiscal Year 2002). Six-inch diameter casing and 0.020 -inch slot screen with 10 to 20-mesh sand filter pack werc placed in the borchole. The remaining annular space (as the casing was removed) was filled with bentonite and grout sealant material. Smearing of the outside of the hole occurs as the casing is driven and as it is removed. The purpose of development in well construction is to repair formation damage. The present program of well development may or may not have repaired the formation damage from drilling operations. Well development was done by surging within the screen during and after placement of the filter pack. Some additional development occurred during the pumping of the well.

The development program for the barrier injection wells likely did not achieve full repair of the formation damage caused by drilling, particularly near the bottom of the well where smearing of clay from the Ringold Upper Mud would be most severe. Remaining formation damage not only makes the well hydraulically less efficient, but also results in injection of the lixiviant not in direct proportion to the hydraulic properties of the aquifer. High-velocity water jetting is probably needed to fully repair the formation damage caused by drilling in existing wells and is recommended for future well construction effors.

The TAT recommends that the effectiveness of well development in the existing barrier wells should be evaluated by comparing the results of the two borehole geophysical logs, which can provide an indication of permeability with depth, to the EBF measurements, which report relative hydraulic conductivities with depth. Lack of correlation of the borchole geophysics and the EBF will indicate problem intervals where formation damage remains a problem due to incomplete well development. This study should be completed before the barricr extension wells are installed so that lessons learned can bc applied to the new wells. The TAT also recommends that existing wells with significant formation damage be re-developed.

\subsection{Alternative pH Buffering of Dithionite Solutions}

If dithionite re-injection is selected as the or part of a preferred option for mending of the barrier, the TAT recommends that an alternative $\mathrm{pH}$ buffer be considered in order to significantly lower the cost of the treatment. Much of the cost of emplacing the ISRM barricr has been due to the chemical buffers used to maintain elevated pH. The buffer cost can be as much as 4 times the cost of the dithionite. Potassium carbonate (sometimes mixed with potassium bicarbonate) has been routinely used at the Hanford Site, and in other projects based on the experience at Hanford. The purpose of maintaining high $\mathrm{pH}$ is to decrease the disproportionation of dithionite, to increase the rate of ferric iron reduction, and to increase adsorption of $\mathrm{Fe}$ (II) onto sediments.

To clevate $\mathrm{pH}$, sodium hydroxide may be used in lieu of potassium carbonate. Sodium hydroxide is commonly used to control $\mathrm{pH}$ for industrial uses of dithionite (such as the paper industry), because it is less expensive than other $\mathrm{pH}$-control agents. In addition to elevating $\mathrm{pH}$, it is necessary to provide sufficient $\mathrm{pH}$-buffering capacity to neutralize the 
WMP-28119

Revision 0

acid produced from dithionite oxidation. Indigenous calcium carbonate minerals may provide the needed buffering capacity.

The TAT made a rough calculation to determine if sufficient calcium carbonate is present in the subsurface at Hanford to provide the required buffering capacity. The following parameter values were assumed:

- injection radius $=30 \mathrm{ft}$,

- injection thickness $=15 \mathrm{ft}$,

- bulk density $=1.8 \mathrm{~kg} / \mathrm{L}$,

- injection dithionite concentration $=0.1 \mathrm{~m} \mathrm{~S}_{2} \mathrm{O}_{4}$,

- injection volume $=40,000$ gal.

- onc mole of $\mathrm{S}_{2} \mathrm{O}_{4}$ is oxidized fully to $\mathrm{SO}_{4}$ yielding 8 moles of $\mathrm{H}^{+}$.

With these assumptions, about 0.6 weight $\%$ of calcite is sufficient to buffer the system. Carbonate is present in the Hanford sediments, possibly at concentrations exceeding 0.6 $\%$; however, it is uncertain if the rate of buffering is sufficient to maintain the required $\mathrm{pH}$. Bench-scale tests are needed to determine the effectiveness of sediment buffering.

PNNL recognizes the importance of developing a lower cost buffer and has conducted research to address this issue. During our review, the TAT was provided with benchscale data on the effectiveness of sediment buffering. However, the bench-scale tests used sediment from the Ft. Lewis site instead of the Hanford site. Other tests may have been conducted using Hanford sediment; however, no data were available for our review. The Ft. Lewis sediment appears to have little sedimentary carbonate as suggested by the low $\mathrm{pH}$ values (about 2.5 ) achieved after only a few column pore volumes of dithionite treatment; it may not be representative of the Hanford sediment.

Although, relevant work has been conducted into the use of altemate $\mathrm{pH}$ buffers, the TAT believes that site-specific bench-scale tests are warranted because of the substantial cost of buffering. Tests of sodium hydroxide, calcium carbonates, magnesium carbonate, and combinations of buffers may yield useful results.

\subsection{Barrier Operations to Accommodate Preferential Pathways}

Operation of the barrier in areas where high hydraulic-conductivity preferential pathways are present may require development of different operational procedures. The TAT recommends that a cost comparison of broad application of a low-cost lixiviant be compared to targeted application of lixiviant to preferential pathways. If the targeted application of lixiviant is the lower-cost alternative, a program of supplemental injection within zones of high hydraulic conductivity should be formulated based on depth-discrete estimates of groundwater flow velocities and abundance of iron. The supplemental injection program may include repeated dosing with the preferred chemical agent. Based upon the results of the depth-discrete aquifer characterization investigation, it is possible that injection wells be designed so that preferential pathways can be packed off for targeted supplemental treatment. 
WMP-28119

Revision 0

This page intentionally left blank 
WMP-28119

Revision 0

\subsection{SUMMARY RECOMMENDATIONS}

\subsection{Recommendations Related to Understanding the Problem}

The TAT believes that the primary reasons for the premature breakdown of the reductive capacity of the aquifer at the 100-D ISRM barrier are: 1) physical and chemical aquifer heterogeneity and 2) presence of oxidants other than $\mathrm{Cr}$, which consume significant percentages of the reductive capacity. Physical heterogeneity is likely producing preferential pathways where quantitics of untreated, oxidative and nitrate-rich groundwater significantly greater than predicted are flowing through the barrier. Chemical heterogeneities may likely be found where significant intervals, likely the preferential pathways, contain insufficient reactive iron to maintain the dithionite-reduccd state in the aquifer. $\mathrm{NO}_{3}{ }^{-}$and $\mathrm{O}_{2}$ consume more than $97 \%$ of the lixiviant injected into the aquifer.

The TAT recommends a detailed, depth-discrete investigation to characterize aquifer heterogeneity (both preferred flow paths and reductive capacity) be conducted using a number of tools to cnhance the understanding of aquifer conditions at the existing barrier location and the planned barrier extension, if installed. Specific tools to address this problem were evaluated by the TAT to develop a list of prioritized technologies (see section 3.5). The minimum set of tools recommended for the depth-discrete characterization include:

- depth-discrete core analysis for physical and chemical parameters (focused on reductive capacity, and amount, distribution, and form of iron, $\mathrm{Cr}$, and sulfur and association among these elements);

- borehole geophysical logging: neutron-neutron and natural gamma; and,

- EBF measurements (relative hydraulic conductivity).

Limited application of tracer and hydraulic tests should also be conducted to provide quantitative data that can be utilized to design the barrier mending activity.

Details regarding recommendations for the aquifer investigation program are provided in Section 3.0. Depending upon the available budget, lower priority technologies should also be considered for testing on a limited basis. Technologies such as the passive flux meter, FLUTe, and cross-borehole geophysics could also be considered for limited testing.

The TAT recommends the following approach to aquifer characterization:

1) conduct geophysical logging and perform EBF measurements in all existing wells;

2) utilize the data collected in \#1 and all prior data to construct the 3-D conceptual model detailing geology, hydrology, chemistry (groundwater and aquifer materials) along the existing barrier;

3) utilize the conceptual model to target locations for drilling of new boreholes in the vicinity of barrier breakthrough; 
WMP-28119

Revision 0

4) collect and analyze data from the new boreholes, including geophysical logging and EBF measurements; conduct limited tracer and hydraulic tests;

5) refine the conceptual model based upon newly collected data; and,

6) utilize the refined conceptual model to design bench-scale tests focused on mending of the existing barrier.

The TAT believes that ISRM barrier longevity calculations were performed based upon a homogeneous aquifer model. Barrier design and operation also assumed a homogeneous aquifer. Because several lines of evidence point towards the presence of preferential flow paths and possibly limited amounts of reactive iron as the primary causes of the premature breakdown in the ISRM barrier, future barrier design and operations must take into account the physical and chemical aquifer heterogeneity. In addition, the presence of co-contaminants, such as nitrate and oxygen, are likely to have significantly reduced the reductive capacity of the aquifer, thus shortening its longevity.

\subsection{Recommendations for Mending the Barrier}

Given the observed physical and chemical heterogeneity of the aquifer, it is very likely that the preferential flow paths may be deficient in reducing equivalents (c.g. reactive iron), which is required for dithionite performance. Mending of the barrier must first involve an evaluation of alternatives, after information is obtained from the aquifer characterization investigation. It is likely that the optimal mending regime will include some combination of these alternatives. The enhancement of the current barrier reductive capacity can be achicved by:

- addition of chemical reductants: calcium polysulfide or iron (either solid micro or nano zero-valent iron or aqueous ferrous iron); and,

- addition of biological reductants either within the injection wells, alone or as a supplement to a chemical reductant, or up-gradient of the present barrier to remove all or a portion of the $\mathrm{O}_{2}$ or $\mathrm{NO}_{3}{ }^{-}$from the groundwater, thereby saving a greater percentage of the barrier's reducing capacity for $\mathrm{Cr}(\mathrm{VI})$ reduction.

These alternatives should be compared to dithionite re-injection, which is considered to be the current baseline.

Because the above alternatives range widely in cost, the TAT recommends that a preliminary cost analysis be conducted to determine the feasibility of using these reductants for mending the barrier. The preliminary cost analysis can be used to screen out approaches that appear to be cost-prohibitive. The remaining alternatives should be examined by bench-scale testing, with particular focus on long-term performance to enable prediction of barrier longevity.

The TAT also recommends controlling/climinating the groundwater mounding and flow perturbations that result form leakage of the 182-D Reservoir to reduce the volume of oxic water flushing the barrier. 
WMP-28119

Revision 0

If dithionite re-injection is selected as the preferred option, the TAT recommends the following:

1) an altemative, lower-cost buffer; and,

2) no extraction following injection, thus allowing for a supplemental biostimulation that promotes reduction of sulfate by SRBs.

\subsection{Recommendations for Extending the Barrier}

The TAT recommends that plans for barrier extension should be made after the existing barrier has been mended. Thus, information on aquifer heterogeneity and mending alternatives can be utilized as lessons leamed in planning the extension. A depth-discrete aquifer characterization investigation must be conducted in the vicinity of the extension in order to ensure appropriate design of the barrier. Specifics of this investigation can build upon lessons leamed from the aquifer characterization investigation recommended for the existing barrier. Well installation/development procedures should utilize recommendations from this report to look at alternatives for drilling and well development. A design and operational approach for the barrier extension should be developed after the depth-discrete aquifer characterization is completed. Reductant selection may likely be the same as was used for mending of the existing barrier, unless significant differences are identified during the aquifer characterization study. 
WMP-28119

Revision 0

This page intentionally left blank 
WMP-28119

Revision 0

\subsection{REFERENCES}

Annable, M.D., K. Hatfield, J. Cho, B. Parker, J. Cherry, 2003, Field Evaluation of the Passive Flux Meter, Joumal of Contaminant Hydrology (In preparation).

Benz, M., A. Brune, A., B. Schink, 1998, Anaerobic and Aerobic Oxidation of Ferrous Iron at Neutral pH by Chemoheterotrophic Nitrate-Reducing Bacteria., Archives of Microbiology, 169:159-165.

Cantrell, K. C., and D. I. Kaplan, 1999, In-Situ Chemical Barrier and Method of Making, Patent Number 5,857,810.

Cantrell, K. J., and D. I. Kaplan, 1997, Zero-valent Iron Colloid Emplacement in Sand Columns, J. Environmental Engineering, 123:499-505.

Cantrell, K. J., D. I. Kaplan, and T. J. Gilmore, 1997a, Injection of Colloidal Size Particles of $\mathrm{Fe}^{\mathbf{0}}$ in Porous Media with Shear-thinning Fluids as a Method to Emplace a Permeable Reactive Zone, Land Contamination \& Reclamation 5(3):253-257.

Cantrell, K. J., D. I. Kaplan, and T. J. Gilmore, 1997b, Injection of Colloidal Fe ${ }^{0}$ Particles in Sand Columns with Shear-thinning Fluids, J. Environmental Engincering 123:786-791.

Chhabra, R.P. 1993. Bubbles, Drops, and Particles in Non-Newtonian Fluids, CRC Press, Boca Raton, Florida.

Department of Energy, 2004, Fiscal Year 2003 Annual Summary Report for In Situ Redox Manipulation Operations, DOE/RL-2004-06, Rev.0, U.S Department of Energy, Richland Operations Office, Richland, Washington

Elliot, D. and W.X. Zhang. 2001. Field Assessment of Nanoscale Bimetallic Particles for Groundwater Treatment, Environmental Science and Technology, Vol. 35 (4), p. 4922.

Emerson, D. and C.L. Moyer, 1997, Isolation and Characterization of Novel IronOxidizing Bacteria that Grow at Circumneutral pH, Applied Environmental Microbiology, 63:4784 4792.

Ernstsen,V., 1996, Reduction of Nitrate by $\mathrm{Fe}^{+2}$ in Clay Minerals, Clays and Clay. Minerals, 44:599-608.

Fendorf, S., B.W. Wielinga, and C.M. Hansel, 2000, Chromium Transformations in Natural Environments: The Role of Biological and Abiological Processes in Chromium (VI) Reduction, Int. Geol., In Press. 
WMP-28119

Revision 0

Freeze, R.A. and J.A. Cherry. 1979. Groundwater. Prentice-Hall, Englewood Cliffs, New Jersey.

Fruchter, J.S., C.C. Cole, M.D. Williams, V.R. Vermeul, J.E. Amonette, J.E. Szecsody, J.D. Istok, and M.D. Humphrey, 2000, Creation of a Subsurface Permeable Treatment Zone for Aqueous Chromate Using In Situ Redox Manipulation, Ground Water Monitoring \& Remediation, Spring: 66-77.

Glazier, R., R. Venkatakrishnan, F. Gheorghiu, L. Walata, R. Nash and W. Zhang. 2003. Nanotechnology Takes Root, Civil Enginecring, Vol. 73 (5), pp. 64-69.

Güven O, R.W. Falta, F.J. Molz, and J.G. Melville, 1985, Analysis Interpretation of Single-wcll Tracer Tests in Stratified Aquifers, Water Resources Research, 21(5): 676684.

Halevy E, H Moser, O Zellhofer, and A Zuber, 1966, Borehole Dilution Techniques - a Critical Review, In Isotopes in IJydrology. International Atomic Energy Agency, Vienna, Austria.

Hall, S.H., 1993, Single Well Tracer Tests in Aquifer Characterization, Ground Water Monitoring \& Review, 13(2): 118-124.

Hall, S.H., S.P. Luttrell, and W.E. Cronin, 1991, A Method for Estimating Effective Porosity and Ground-water Velocity, Ground Water, 29(2):171-174.

Hansen, H., C.B. Koch, H. Nancke-Krogh, O.K. Borggaard, J. Sørensen, 1996, Abiotic Nitrate Reduction to Ammonium: Key Role of Green Rust, Environmental Science and Technology, 30:2053-2056.

Hatfield, K., P.S.C. Rao, M. Annable, and T. Campbell, 2002, Device and Method for Measuring Fluid and Solute Fluxes in Flow Systems, Patent US 6,402,547B1.

Hatfield, K., M. Annable, J. Cho, P.S.C. Rao, and H. Klammler, 2003, A Direct Method for Measuring Water and Contaminant Fluxes in Porous Media, Contaminant Hydrology (Accepted).

Kaplan, D.I., K.J. Cantrell, T.W. Wietsma and M.A. Potter, 1996, Formation of a Chemical Barrier with Zero-valent Iron Colloids for Groundwater Remediation, J. Environmental Quality, 25, 1086-1094.

Kaplan, D.I., K.J. Cantrell, and T.W. Wietsma, 1994, Formation of a Barrier to Groundwater Contaminants by the Injection of Zero-valent Iron Colloids: Suspension Properties." In In-situ remediation: Scientific basis for current and future technologies (eds. G. W. Gee and N. R. Wing), pp. 820-838. Battelle Press, Columbus, Ohio. 
WMP-28119

Revision 0

Klammler H., K. Hatfield, and M. Annable, 2003, Distortion of the Uniform

Groundwater Flow Field Duc to a Permeable Passive Flux Meter in a Borehole with Well Screen and Filter Pack, Joumal of Contaminant Hydrology, (In Review).

Komori, K. Rivas, A., Toda, K., and Ohtake, H., 1990, A Method for Removal of Toxic Chromium Using Dialysis-Sac Cultures of a Chromate-Reducing Strain of EnterobacterCloacac, Applied Microbiology Biotechnology, v. 22, \#1, p. 117-119.

Leap, D.I. and P.G. Kaplan, 1988, A Single-Well Tracing Method for Estimating Regional Advective Velocity in a Confined Aquifer: Theory and Preliminary Laboratory Verification, Water Resources Research 24(7): 993-998.

Lind, A.M., H.M. Golterman, Ed, 1983, in Denitrification in the Nitrogen Cycle, Plenum, New York, pp 145-156.

Loeppert, R.L., and W.P. Inskeep, 1996, Iron in Methods of Soil Analysis. Part 3:

Chemical Methods. D.L. Sparks, et. al., eds. Soil Science Society of America. Madison, WI.

Losi, M.E., Amrhein, C., and Frankengerger, W.T.J., 1994, Bioremediation of ChromateContaminated Groundwater.by Reduction and Precipitation in Surface Soils, Journal of Environmental Quality, v. 23, p. 1141-1150.

Lovley, D.R., 1993, Dissimilatory Metal Reduction, Annual Review of Microbiology, v. 47, p. 263-290.

Lovley, D.R. and J.D. Coates, 1997, Bioremediation of Metal Contamination, Current Opinion in Biotechnology, v. 8, \#3, p. 285-289.

Molz, F.J., J.G. Melville, O. Güven, R.D. Crocker, and K.T. Matteson, 1985, Design and Performance of Single-Well Tracer Tests at the Mobile Site, Water Resources Research 2I(10): 1497-1502.

Morrison, S.J., R.R. Spangler, and S.A. Morris, 1996, Subsurface Injection of Dissolved Ferric Chloride to Form a Chemical Barrier: Laboratory Investigations, Ground Water, v. 34, pp. 75-83.

Ottley, C.J., W. Davison, W.M. Edmunds, 1997, Chemical Catalysis of Nitrate Reduction by Iron(II), Geochimica Cosmochimica Acta , 67:1819-1828.

Pekala, M., D. Oleszak, E. Jartych, and J.K. Zurawicz, 1999, Structural and Magnetic Study of Crystalline Fe80Ni20 Alloys with Nanometer-sized Grains. Journal of NonCrystalline Solids, Vol. 252, pp. 757-761.

Petersen, H.J.S, 1979, Acta Chem. Scand., 33:795-796. 
Pcttinc, M., L., D.O., L. Campanella, F.J. Millero, and R. Passino, 1998, The Reduction of Chromium (VI) by Iron (II) in Aqueous Solutions, Geochimica Cosmochimica Acta, 62(\#9): 1509-1519.

Pickens J.F., and G.E. Grisak, 1981, Scale-dependent Dispersion in a Stratified Granular Aquifer, Water Resources Rescarch 17(4): 1191-1211.

Ponder, S., J.G. Darab, J. Bucher, D. Caulder, I. Craig, L. Davis, N. Edelstein, W. Lukens, H. Nitsche, L. Rao, D.K. Shuh, and T.E. Mallouk, 2001, Surface Chemistry and Electrochemistry of Supported Zerovalent Iron Nanoparticles in the Remediation of Aqueous Metal Contaminants. Chem. Materials Vol. 13 (2), pp. 479-486.

Postma, D., 1990, Kinetics of Nitrate Reduction by Detrital Fe(II) Silicates, Geochimica Cosmochimica Acta, 54:903-908.

Revesz, A. et al, 2000, Melting Point Depression and Microstructure in Ball-Milled Nanocrystalline Aluminum Powders. Journal of Metastable and Nanocrystalline Materials, Vol. 8, pp. 326-332.

Sass B. M. and D. Rai, 1987, Solubility of Amorphous Chromium (III)-Iron(III) Hydroxide solid Solutions, Inorg.Chem. 26, 2228-2232.

Rouse, J.V., M.C.Leahy, and R.A. Brown, 1996, A Geochemical Way to Keep Metals at Bay, Environmental Enginecring World, May-June, 1996.

Spane, F.A., Jr., P.D. Thome, and D.R. Newcomer, 2003, Results of Detailed Hydrologic Characterization Tests - FY 2002. PNNL-14186. Pacific Northwest National Laboratory, Richland, Washington

Straub, K.L., M. Benz, B. Schink, F. Widdel, 1996, Anaerobic, Nitrate-Dependent Microbial Oxidation of Ferrous Iron, Applied Environmental Microbiology, 62:14581460.

Vermeul, Vince, 2004, Characterization of Formation Heterogeneities at the 100-D Area ISRM Treatability Test Site, presentation March 2004, Richland WA.

Waldrop, William R. and Hubert S. Pearson, 2002a, Results of Field Tests with the Electromagnetic Borchole Flowmeter at the 100-D Area In Situ Redox Manipulation Barrier Site, QEC-T-146.

Waldrop, William R. and Hubert S. Pearson, 2002b, Second Phase of Testing with the Electromagnetic Borehole Flowmeter at the 100-D Area In Situ Redox Manipulation Barrier Site, QEC-T-147.

Wang, C. and Zhang, W., 1997, Nanoscale Metal Particles for Dechlorination of PCE And PCBs, Environmental Science and Technology, Vol. 31 (7), p. 2154. 
WMP-28119

Revision 0

Weber, K.A., F.W. Picardal, E.E. Roden, 2001, Microbially Catalyzed Nitrate-Dependent Oxidation of Biogenic Solid-Phase Fe(II) Compounds, Environmental Science and Technology., 35:1644-1650

Wielinga, B., Mizuba, M.M., Hansel, C.M., and Fendorf, S., 2001, Iron Promoted Reduction of Chromate by Dissimilatory Iron-Reducing Bacteria, Environmental Science and Technology, v. 35, \#3, p. 522-527.

Williams, M.D., V.R. Vermeul, J.E. Szecsody, and J.S. Fruchter, 2000, 100-D Area In Situ Redox Treatability Test for Chromate-Contaminated Groundwater, Prepared for USDOE by PNNL (Contract No.: DE-AC06-76RLO 1830), Richland, WA.

Zhang, W., 2003, Nanoscale Iron Particles for Environmental Remediation: an Overview. Journal of Nanoparticle Research, Vol. 5, pp. 323-332. 
WMP-28119
Revision 0

$\begin{array}{rr}-1 & \\ \text { WMP-28119 } & \text { Revision } 0\end{array}$

This page intentionally left blank 
WMP-28119

Revision 0

APPENDIX A: TECHNICAL ASSISTANCE REQUEST 

TECINICAL ASSISTANCE REQUEST

Tracking Number:

Request Title: $\quad$ Mending the In Situ Redox Manipulation Barrier - Fluor

Hanford/Groundwater Protection Program

Contact

Individual:

MS McCormick-RL, JA Frcy-RL, KM Thompson - RL

Requesting

Organization:

Richland Operations Office

E-Mail Address:
Matthew S McCormick@rl.gov
Jeffrey A Frey@rl.gov
KM Mike Thompson@rl.gov

Phone Number:

\begin{tabular}{|l|}
\hline 509-373-9971 \\
(McCormick) \\
$509-376-7727$ (Frey) \\
509-373-0750 \\
(Thompson) \\
\hline
\end{tabular}

Fax Number:
509-372-3548
(McCormick)
509-376-0306 (Frey)
509-372-1926
(Thompson)

\section{Scope of Work:}

Technical Assistance is requested to help determine the cause of premature failure in some of the wells at Hanford's 100-D Area, and alternatives for repairing the breakdown. The current solution is to reinject wells that show signs of premature breakdown with the strong reductant sodium dithionite, but this approach is both costly and short-lived. 
Hanford's In Situ Redox Manipulation (ISRM) permeable reactive barrier is showing signs of failure after only a few years of operation. This situation impacts final closure of the 100-HR-3 Operable Unit; ISRM must be shown to be robust and reliable to be considered a final solution. The Washington State Department of Ecology has requested that the ISRM barrier be immediately extended to intercept a spreading groundwater plume.

The ISRM barrier forms a $680 \mathrm{~m}$ long zone of reduction to intercept and reduce a $\mathrm{Cr}$ (VI) plume before it reached the Columbia River. It was emplaced from 1997 to 2003 by drilling boreholes into the aquifer and injecting sodium dithionite, which reduces the native ferric iron in the aquifer materials to ferrous iron. After allowing approximately 36 hours for reaction, the residual reagent and byproducts are extracted from the aquifer. As contaminated groundwater passes through the treated zone, ferrous iron in the formation reduces the mobile and toxic $\mathrm{Cr}(\mathrm{VI})$ to $\mathrm{Cr}(\mathrm{III})$, which is much less toxic and nearly immobile in groundwater.

Before the barrier was emplaced extensive field and laboratory tests were undertaken to cvaluate the feasibility of this technology. The tests indicated that the barrier should maintain its reductive capacity for approximately 20 years. However, less than three years after emplacement, $\mathrm{Cr}$ levels in some of the five initial treatability test wells began rising, indicating loss of reductive capacity. Five wells were reinjected with sodium dithionite in 2002 to reestablish their reductive capacity. Since then, four other wells have begun to show signs of breakdown.

The cause of premature breakdown in reductive capacity is unknown, but may relate to one or more of the following conditions:

- Heterogeneity (rapid re-oxygenation of high-flow velocity zones)

- Fluctuating water table (oxygenation from water level decline)

- Variability in reduced iron content and other geochemical indicators

- Re-oxygenation of reduced zone during air rotary drilling

- Formation disturbance (fracturing) / trapped air from air rotary drilling

- Natural re-oxygenation rates (dissolved oxygen content in the natural groundwater)

\section{Technical Assistance Approach}

A long-term solution to the problem of premature loss of reductive capacity in ISRM wells is desired. To that end, the Richland Operations Office requests that a team of experts be assembled to evaluate the current situation and propose one or more viable solutions. The team will be provided with documents and information on the construction and monitoring of the ISRM barrier, as well as investigations into the causes of breakdown conducted to date. After sufficient time for the team to absorb this material, a two-day meeting will be held at Richland to discuss the problem and 
WMP-28119

Revision 0

produce a technology plan for an enduring solution to reoxygenation of the ISRM wells.

The team should have expertise in geochemistry and hydrogeology, as well as broad knowledge of innovative groundwater remediation technologies. Some suggested members of the team are:

Miles Denham - SRS

Tom Early - ORNL

Terry Sullivan - BNL

Kirk Cantrell - PNNL

John Fruchter - PNNL

The goals of this Technical Assistance are to evaluate the most likely cause(s) of breakdown in individual wells, and propose long-term solution(s) for $\mathrm{Cr}$ reduction. The tcam should be available to travel to Richland for at least 2 days of mectings with site personnel. These meetings should occur within two months of the issuance of this Technology Assistance request. A report with the team's analysis of the situation and recommended solution should be issued shortly thereafter.

DOE-RL will support this project by providing in-kind support for site personnel. This will include preparation and transmittal of briefing materials, site meetings, and closeout meetings. There is also a possibility of supporting tests and/or deployment of one or more promising technologies to solve premature breakdown of the ISRM barrier. 
WMP-28119

Revision 0

Support:

What resource(s) have been selected?

Tentative Schedule

Select Technical Assistance Team - December 22, 2003

Provide information to Technical Assistance Team - January 15, 2004

Meetings in Richland - February 3 \& 4, 2004

Final report - March 12, 2004

What resources were offered, but not selected?

N/A

Requested Start Date:

$12 / 22 / 03$

Requested Completion Date: $3 / 12 / 04$

Submitted By:

Jeffery A. Frey.

Approved By: Matt McCormick, $\Lambda$ MCP 


\section{OFFICE OF SCIENCE AND TECHNOLOGY}

\section{WORK AUTHORIZATION/TASK CHANGE REQUEST (TCR)}

Project Number

*:

Mending the Ins

Project Titlc: Protection Program

Sitc

/Contractor: Fluor Hanford
Protccion Program

Date: $11 / 19 / 2003$

FIN Plan

Month: $\mathbf{n} / \mathbf{a}$

Mending the In Situ Redox Manipulation Barrier - Fluor Hanford/Groundwater

OST Project Tech

Area: Assistance
Work Proposal

Attached: $\mathrm{Y}$

\begin{tabular}{|c|c|c|c|c|c|c|c|}
\hline \multicolumn{3}{|c|}{ * Increase to this Project } & \multicolumn{5}{|c|}{ Decrement Source } \\
\hline $\begin{array}{l}\text { B\&R } \\
\text { Code }\end{array}$ & $\begin{array}{l}\text { BA } \\
\$ K\end{array}$ & BO \$K & $\begin{array}{l}\text { Project } \\
\text { Number }\end{array}$ & $\begin{array}{c}\text { Contracto } \\
\mathbf{r}\end{array}$ & $\begin{array}{l}\text { B\&R } \\
\text { Code }\end{array}$ & BA \$K & BO \$K \\
\hline $\begin{array}{l}\text { EY404911 } \\
0\end{array}$ & $\$ 50 \mathrm{~K}$ & & & & & $\$ 50 \mathrm{~K}$ & \\
\hline & & & & & & & \\
\hline
\end{tabular}

Description

of Work

Scope

Authorized

Determine the cause of breakdown in some of the In Situ Redox Manipulation (ISRM) permcable reactive barrier wells at Hanford's 100-D Area, and altematives for repairing /Changed:

the breakdown.

Submitted by:

Date:

Headquarters Project Manager

Accepted by:

Date:

Field Representative

Approved by:

Date:

Project Area Manager/ Office Director, OST

The following Budget Representative from the DOE Field Offices referenced in Decrement Sources has provided EM-12 the attached certification of funds available for withdrawal in connection with this AFP change:

Source: 

WMP-28119

Revision 0

This page intentionally left blank

B-ii 
WMP-28119

Revision 0

WORKSHOP ATTENDEES

Technical Assistance Workshop

Mending the In Situ Redox Manipulation Barrier

March 2-4, 2004

\begin{tabular}{|l|l|l|l|}
\hline \multicolumn{1}{|c|}{ NAMIE } & \multicolumn{1}{|c|}{ COMIPANY } & \multicolumn{1}{c|}{ PIIONE } & \multicolumn{1}{c|}{ e-MIAIl } \\
\hline Jim Szecsody & PNNL & $509-372-6080$ & jim.szecsody@pnl.gov \\
\hline Vince Vermeul & PNNL & $509-376-8316$ & vince.vermeul@pnl.gov \\
\hline John Fruchter & PNNL & $509-376-3937$ & john.fruchter@pnl.gov \\
\hline Dale Ralston & $\begin{array}{l}\text { Ralston } \\
\text { Hydrogeological } \\
\text { Services }\end{array}$ & $208-883-0533$ & ralston@moscow.com \\
\hline Dib Goswami & Ecology & $509-735-3015$ & Dgos461@ECY.WA.gov \\
\hline Scott Petersen & Fluor Hanford & $509-372-9126$ & scott_w_petersen@rl.gov \\
\hline Bruce Wielinga & MFG, Inc. & $970-223-9600$ & bruce.wielinga@mfgenv.com \\
\hline Stan Morrison & SM Stoller & $970-248-6373$ & smorrison@gjo.doe.gov \\
\hline Rajat Ghosh & RETEC & $412-380-0140$ & rghosh@rctec.com \\
\hline Tom Fogwell & Fluor Hanford & $509-373-3812$ & thomas_fogwell@rl.gov \\
\hline J.Price & Ecology & $509-736-3029$ & JPRI461@ECY.IVA.gov \\
\hline J. Isaacs & Fluor Hanford & $509-373-3805$ & jared_d_isaacs@rl.gov \\
\hline Kirk Cantrell & PNNL & $509-376-2136$ & kirk.cantrell@pnl.gov \\
\hline Dawn Kaback & CTC & $\begin{array}{l}303-297-0180 \\
\text { ext. 111 }\end{array}$ & kabackd@ctc.com \\
\hline Vernon Johnson & Fluor Hanford & $509-378-3987$ & vernon_g_johnson@rl.gov \\
\hline Craig Swanson & Fluor Hanford & $509-373-3807$ & L_Craig_Swanson@rl.gov \\
\hline J.V. Borghese & Fluor Hanford & $509-373-3804$ & Jane_V_Borghese@rl.gov \\
\hline Arlene Tortoso & DOE-RL & $509-373-9631$ & Arlene_C_Tortoso@rl.gov \\
\hline & & & \\
\hline
\end{tabular}


WMP-28119

Revision 0

This page intentionally left blank 
WMP-28119

Revision 0

APPENDIX C: AGENDA

C-i 
WMP-28119

Revision 0

This page intentionally left blank

C-ii 


\author{
DRAFT AGENDA \\ Hanford In Situ Redox Manipulation Technical Assistance Workshop \\ Room 1-Cl, 1200 Jadwin Avenuc \\ Richland WA \\ March 2-4, 2004
}

Tuesday, March 2

$\begin{array}{lll}\text { 8:00-8:15 } & \text { Welcome and Introductions } & \text { Tortoso } \\ \text { 8:15-8:30 } & \text { Workshop Objectives and Logistics } & \text { Petersen and Kaback } \\ \text { 8:30-8:45 } & \text { Background - Regulatory Framework } & \text { Tortoso } \\ \text { 8:45-9:45 } & \text { Background - Design and Performance } & \text { Fruchter, Vermeul } \\ \text { 9:45-10:00 } & \text { Break } & \\ \text { 10:00-10:45 } & \text { Operations } & \text { Isaacs } \\ \text { 10:45-11:15 } & \text { Current Status of ISRM Barricr } & \text { Petersen } \\ 11: 15-11: 30 & \text { Lab Determination of Reductive Capacity } & \text { Szecsody } \\ 11: 30-12: 30 & \text { Lunch } & \\ \text { 12:30-3:30 } & \text { Site Tour (ISRM at 100-D) } & \text { All } \\ 3: 30-5: 00 & \text { Team Discussions / Workshop Structure } & \text { Team }\end{array}$

Wednesday, March 3

8:00-12:00

12:00-1:00

$1: 00-4: 00$

4:00-5:00

$8: 00-8: 15$

Thursday, March 4

8:00-10:00

10:00-11:00

11:00-12:00
Brainstorming Solutions

Lunch

Evaluation of Options/Recommendations

Discussion/Questions w Fluor \& PNNL
Team

Team

All
Finalization of Recommendation
Team
Preparation of Outbriefing
Team
Out-briefing/Discussion w DOE and Fluor
All 
Page 82 of 93 of DA01912029

WMP-28119

Revision 0

This page intentionally left blank

C-2 
WMP-28119

Revision 0

APPENDIX D: BARRIER LONGEVITY AND THE NITRATE EFFECT

D-i 

WMP-28119

Revision 0

\section{BARRIER LONGEVITY AND THE NITRATE EFFEC}

The longevity of the barrier installed in the 100-D Area at Hanford for the removal of $\mathrm{Cr}(\mathrm{VI})$ was determined based on site-specific data and assumptions (Fruchter et al., 2000), which included:

- average Fe(III) measured in Hanford Formation sediments,

- bulk density and effective porosity,

- concentrations of $\mathrm{DO}$ and $\mathrm{Cr}(\mathrm{VI})$ measured in the field, and

- core data, which indicated that 60 to $100 \%$ of the available Fe(III) was reduced on treatment with sodium dithionite.

$\mathrm{NO}_{3}{ }^{-}$as a potential $\mathrm{Fe}$ (II) oxidant was not factored into the early longevity calculations (Williams, 2000). Review of data collected since the initiation of the ISRM program, however, indicates that nitrate may play a significant role in determining barrier longevity. Figure 5 in the main body of the report compares the concentrations of DO, $\mathrm{Cr}(\mathrm{VI})$ ) and $\mathrm{NO}_{3}{ }^{-}$measured at treatment well 199-D4-7 (D4-7) from January 1999 to December 2003. This figure illustrates two points: 1) nitrate follows a trend similar to that of $\mathrm{DO}$ and $\mathrm{Cr}(\mathrm{VI})$, increasing in concentration as the effectiveness of the barrier decreases at $\mathrm{D} 4-7$, indicating that $\mathrm{NO}_{3}{ }^{-}$was also being reduced by the Fe(II) contained in the barricr; 2) the potential importance of nitrate for consuming the reducing capacity of the barrier, owing to the much greater concentration of $\mathrm{NO}_{3}{ }^{-}$when compared to the other $\mathrm{Fe}$ (II) oxidants (note log scale on y-axis of Figure 5).

The importance of $\mathrm{NO}_{3}{ }^{-}$as an oxidant is further supported by cxamination of $\mathrm{NO}_{3}{ }^{-}$and nitrite concentrations in up-gradient, treatment zone and down-gradient wells. In the upgradient well 199-D4-22 (D4-22), the concentration of $\mathrm{NO}_{3}{ }^{-}$has remained fairly constant ranging between 0.97 to $1.1 \mathrm{mM}(60.4$ to $69.2 \mathrm{mg} / \mathrm{L})$ from late 1999 to the end of 2003 (Figure D-1). In contrast, in treatment zone well D4-7 and down-gradient well 199-D4-1 (D4-1), show increasing nitrate levels after the initial dithionite injection in 1997 and a dramatic drop in concentration after the second treatment in August 2002. At least some of the initial decline in $\mathrm{NO}_{3}{ }^{\circ}$ levels in the injection and nearby down-gradient monitoring wells may have been the result of dilution effects, but the continued low levels observed currently suggest that $\mathrm{NO}_{3}{ }^{-}$reduction is occurring within the treatment zone. 
WMP-28119

Revision 0

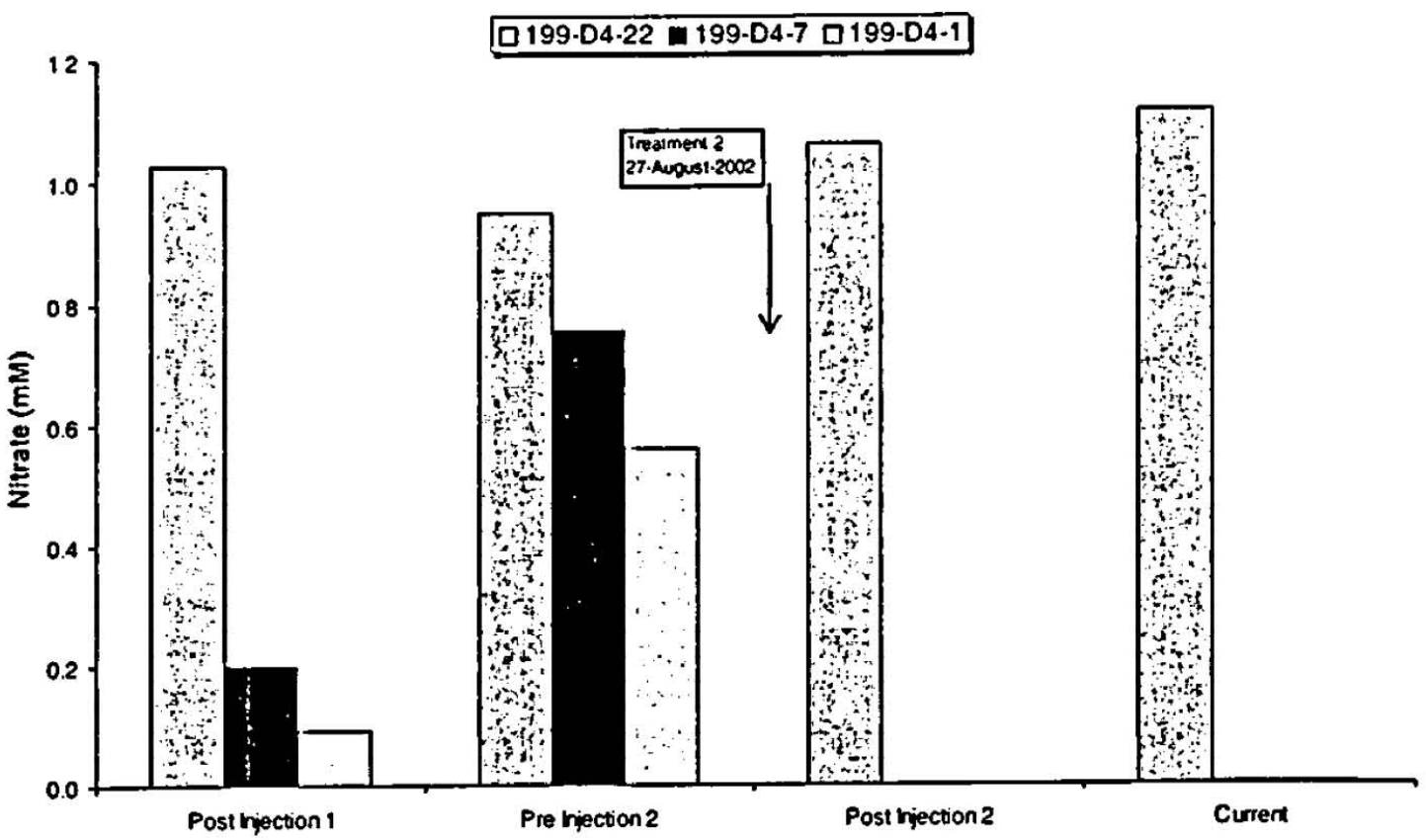

Figure D-1. $\mathrm{NO}_{3}{ }^{\circ}$ concentrations measured in up-gradient (199-D4-22), treatment zone (199-D4-7), and down-gradient (199-D4-1) wells prior to re-treatment of well D4-7 in August 2002.

A concomitant increase in the concentration of nitrite in well D4-7 immediately following the August 2002 dithionite injection indicates that at least a portion of the nitrate lost was converted to nitrite (Figure D-2). However, the increase in the level of nitrite (on a molar basis) is only a fraction of the amount of nitrate removed, suggesting that nitrate is potentially transformed to more reduced phases, such as $\mathrm{N}_{2}$ gas or ammonia. In addition, nitrate and nitrite levels have remained very low, $0.002 \mathrm{mg} / \mathrm{L}$ and $0.007 \mathrm{mg} / \mathrm{L}$ respectively as of December 2003, indicating that nitrate continues to be reduced to phases other than nitrite. 


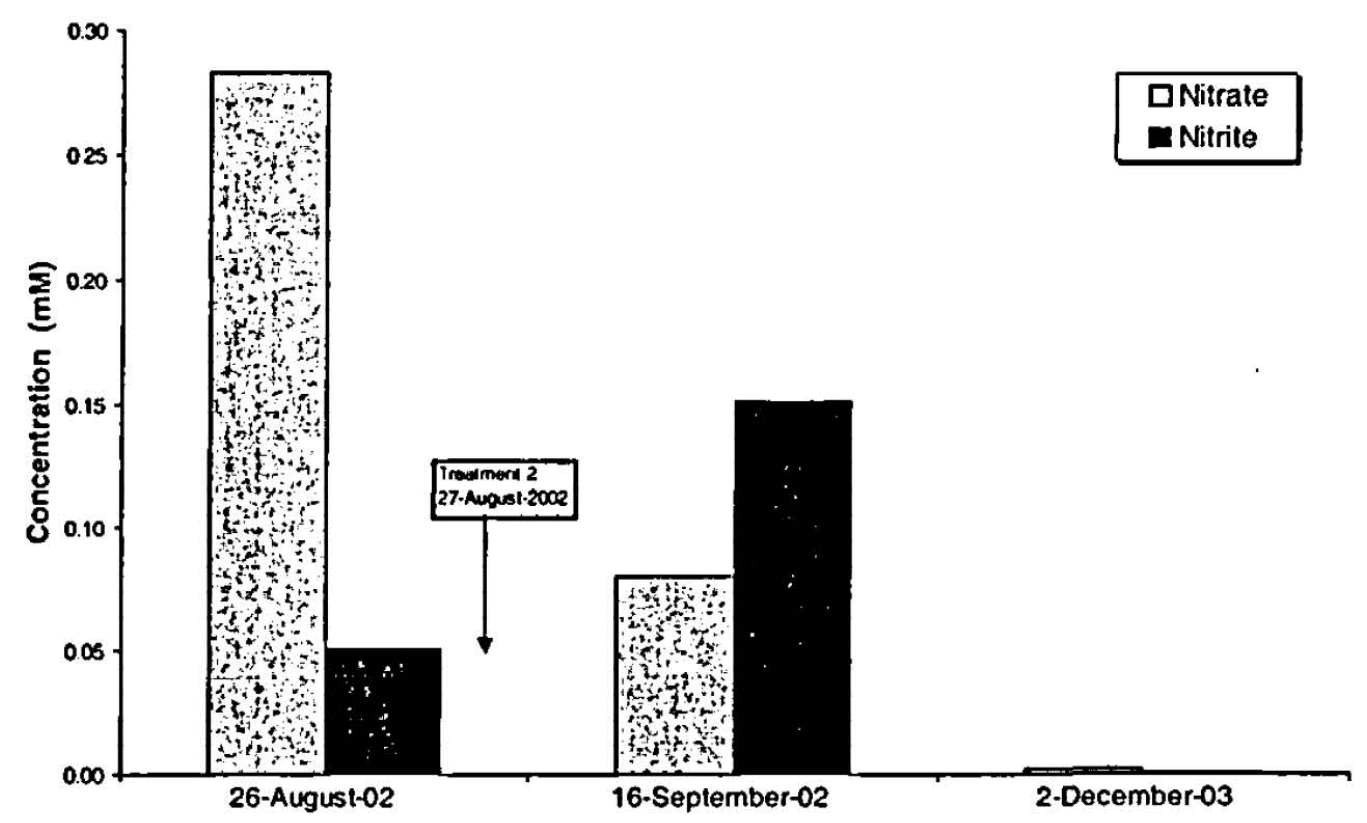

Figure D-2. Comparison of $\mathrm{NO}_{3}{ }^{-}$and nitrite concentrations measured at well 199 D4-7 before and after the second sodium dithionite injection, 27-August-2002.

There is evidence in the literature for anoxic $\mathrm{Fe}$ (II) oxidation by $\mathrm{NO}_{3}{ }^{-}$in sedimentary environments (Emerson and Moyer, 1997; Lind, 1983; Postma, 1990; Ernstsen, 1996; and Emstsen et al., 1998). However, the abiotic reduction of $\mathrm{NO}_{3}{ }^{-}$by $\mathrm{Fe}(\mathrm{II})$ at circumncutral pH typically occurs at high temperatures (Petersen, 1979), in the presence of very reactive $\mathrm{Fe}$ (II) phases, such as green rust (Hansen et al., 1996), or in the presence of a catalyst (Ottley, et al., 1997). Recent investigations however, have demonstrated the anaerobic oxidation of $\mathrm{Fe}$ (II) coupled to $\mathrm{NO}_{3}{ }^{-}$reduction to $\mathrm{N}_{2}$ at neutral pH by denitrifying bacteria, and in some cases under strict autotrophic conditions (Benz et al., 1998; Straub et al., 1996; and Weber et al., 2001). These studies in concert with the site groundwater data suggest that $\mathrm{NO}_{3}{ }^{-}$is likely consuming reducing equivalents and that the reduction pathway to nitrite is only of minor importance, whereas further reduction to $\mathrm{N}_{2(\text { gas) }}$ and/or $\mathrm{NH}_{3}$ could be the primary operative pathways. 
WMP-28119

Revision 0

This page intentionally left blank 
WMP-28119

Revision 0 APPENDIX E: PNNL ZERO-VALENT IRON EMPLACEMENT EXPERIMENTS 
Revision 0

This page intentionally left blank 
WMP-28119

Revision 0

\section{PNNL ZERO-VALENT IRON EMPLACEMENT EXPERIMENTS}

The high density of iron particles $\left(7.6 \mathrm{~g} / \mathrm{cm}^{3}\right)$ promotes gravitational settling, which apparently is the dominant removal mechanism for $\mathrm{Fe}^{0}$ particles in aqueous solution passing through sand columns (Kaplan et al. 1996; Cantrell and Kaplan 1997). More recent work indicates that particle aggregation is also an important factor. Certain nonNewtonian fluids are shear-thinning, a phenomenon in which the viscosity of the fluid decreases with increasing shear rate (Chhabra, 1993). This property allows the development of a suspension that is viscous enough to keep the particles suspended for extended time periods, but will not cause excessive resistance to flow of the suspension during injection, greatly improving transport of particles through porous media (Cantrelt and Kaplan 1999; Cantrell et al. 1997a,b). Testing of commercially available shearthinning polymers indicated that the properties of the polymer are important in determining its effectiveness for this particular application. One particlularly promising compound, sodium-2-acrylamido-2-methylpropane sulfonate (AMPS), was subjected to batch and column adsorption tests. The results indicated that there was essentially no adsorption to the natural minerals in Hanford sediments, making the polymer a suitable candidate for further testing in soil columns.

Figure E-1 shows results from an injection experiment conducted in a 1.0-meter long column of Hanford sediment. This experiment was conducted by first pre-treating the column with approximately two pore volumes of a solution containing only $0.5 \%$ AMPS at a $\mathrm{pH}$ of 8.0 . Following pretreatment, a slurry composed of $0.5 \%$ AMPS and $1.0 \% \mathrm{Fc}^{0}$ in water ( $\mathrm{pH} \mathrm{8.0)}$ was injected into the soil column. In total, three pore volumes of this slurry were injected at a rate of $7.2 \mathrm{~cm} / \mathrm{min}$ (average linear velocity of fluid). The results indicate a fairly even distribution of iron throughout the column, ranging from $0.5 \% \mathrm{Fe}^{0}$ at $10 \mathrm{~cm}$ from the inlet to about $0.3 \% \mathrm{Fe}^{0}$ at the end of the column.

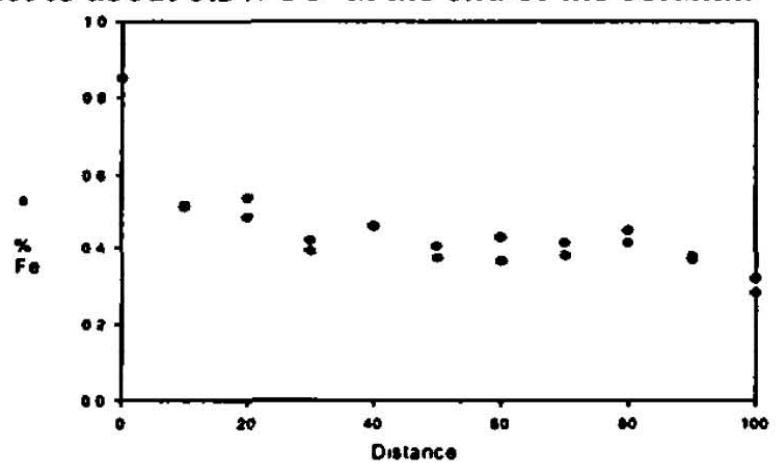

Figure E-1. Distribution of $\mathrm{Fe}^{0}$ in a 100-cm column of Hanford sediment. Slurry composition of $1.0 \% \mathrm{Fe}^{0}$ and $0.5 \%$ polymer in water. 3 pore volumes treatment at a flow-rate of $7.2 \mathrm{~cm} / \mathrm{min}$ after a 2 pore-volume pretreatment with $0.5 \%$ polymer in water.

To determine if the injection of $\mathrm{Fe}^{0}$ into the columns caused any permanent reduction in permeability, a column injection experiment was conducted in an identical fashion to that of the experiment illustrated in Figure 5; however, in this case the inlet pressure was 
monitored prior to, during, and after the injection phase of the experiment. Prior to pretreatment and after $\mathrm{Fe}^{8}$ injection, water was pumped through at a much slower flow rate to determine whether the permeability of the column had changed. Flow-rates for the various steps in this experiment were chosen to model what might occur in a field implementation. Therefore, water injections were conducted at low velocity, which is characteristic of the movement of groundwater in the aquifer.

As can be seen from Figure E-2, injection of water $(0.76 \mathrm{~cm} / \mathrm{min})$ prior to pretreatment resulted in very low-pressure drop across the column $(0.7 \mathrm{psig})$. As the $0.5 \%$ polymer pretreatment solution was injected $(7.0 \mathrm{~cm} / \mathrm{min})$, the pressure drop across the column began to increase. During slurry injection the pressure drop continues to increase. After $\mathrm{Fe}^{8}$ deposition, water $(0.85 \mathrm{~cm} / \mathrm{min})$ was pumped through the column. When this was done, the pressure drop decreased significantly from about 70 psig to 11 psig. This is a significant decrease in backpressure; however, it is significantly higher than the initial backpressure measured prior to pretreatment. After 3.4 pore volumes of water were pumped through the column the pressure drop returned to $0.9 \mathrm{psig}$, indicating the injection process does not cause a significant decrease in permeability to the system. During the final water flush, the iron concentration of the effluent was monitored. There was no evidence of iron in the effluent, which indicates that once the $\mathrm{Fe}^{0}$ deposits in the sediment, it cannot be displaced by normal water flow within the aquifer.

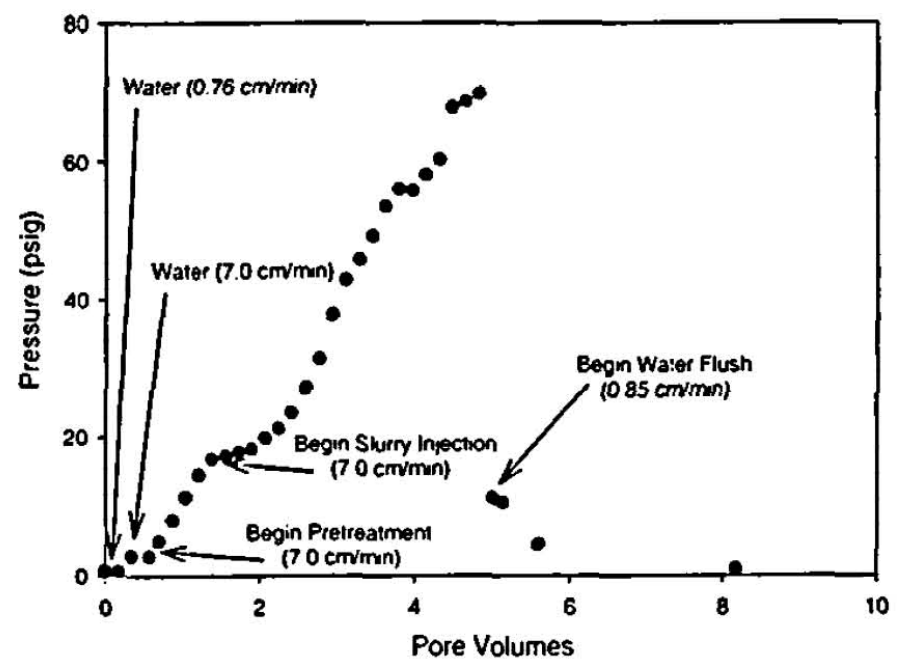

Figure E-2. Inlet back-pressure before, during, and after slurry injection. 
WMP-28119

Revision 0

\section{DISTRIBUTION}

Fluor Hanford

T. W. Fogwell

E6-35

K. K. Schneider (3)

E6-35

S. W. Petersen

E6-35

Pacific Northwest National Laboratory

Hanford Technical Library

P8-55

Lockheed Martin Information Technology

Document Processing Center

H6-08

EDMC

H6-08

Distr - 1 